\title{
Anàlisi bibliogràfica dels estudis sobre traducció i recepció literàries a Catalunya durant el franquisme
}

\author{
JORDI JANÉ-LLIGÉ \\ Grup d’Estudis de la Traducció Catalana Contemporània \\ de la Universitat Autònoma de Barcelona (Espanya) \\ orcid.org/0000-0002-5950-1518
}

Presentació: 20 març 2016 | Acceptació: 22 jul. 2016 | Publicació: 15 des. 2016

Citació recomanada: JANÉ-LLIGÉ, Jordi. «Anàlisi bibliogràfica dels estudis sobre traducció i recepció literàries a Catalunya durant el franquisme». Franquisme \& Transició. Revista d'Història i de Cultura 4 (2016): 257-310. doi: http://dx.doi.org/10.7238/fit.voi4.2960

Resum: L'estudi de les iniciatives de traducció literària al català que s'endegaren durant el franquisme, com també de les circumstàncies en què tingué lloc l'activitat traductora durant aquell període, ha esdevingut en els darrers temps una àrea de recerca molt prolífica a casa nostra. El present estudi bibliogràfic ofereix una descripció històrica del procés de consolidació d'aquest camp de recerca específic a través de l'anàlisi dels treballs d'investigació que immediatament després de la mort de Franco se'n van començar a ocupar i que, d'aleshores ençà, no han parat de créixer.

Paraules clau: censura, franquisme, traducció literària, món editorial, models de llengua literària, estudis de gènere, traductors

\section{Bibliographical analysis of studies on literary translation and reception in Catalonia during the Francoism}

Abstract. The analysis of the literary translation initiatives into Catalan which were set in motion throughout Franco's dictatorship, as well as the analysis of the circumstances under which translation took place at that time have become a very prolific area of research in our countryin recent years. This lit-

Nota: Aquest estudi s'inscriu en el Grup d'Estudi de la Traducció Catalana Contemporània (GETCC) (2014, SGR 285), reconegut per l'Agència de Gestió i Ajuts Universitaris de la Generalitat de Catalunya, i en el projecte «La traducción catalana contemporánea catalana: censura y políticas editoriales, género e ideología (1939-2000)», FFI2014-52989-C2-1-P, finançat pel Ministeri de Ciència i Innovació. 
erature review provides a historical description of the consolidation process that this research area has experienced, based on the analyses of the studies that started to appear immediately after Franco's death and have been growing constantly since then.

Keywords: censorship, Francoism, literary translation, publishing industry, literary language models, gender studies, translators

\section{Introducció}

L’aparició, l'any 2013, de Franquisme \& Transició és un símptoma inequívoc de la rellevància que d'ençà d'alguns anys ha adquirit en el món acadèmic la revisió d'aquests períodes clau del nostre passat recent, tant des del punt de vista estricte dels estudis històrics com de les diverses disciplines relacionades amb la història cultural. Pel que fa a l'anàlisi del paper de la traducció en l'articulació del sistema literari català durant el franquisme, objecte del present estudi bibliogràfic, cal atribuir aquest interès manifest a alguns factors específics, a banda de les causes que han concorregut a despertar el renovellat interès general i que apuntaré seguidament. En primer lloc, doncs, cal circumscriure la proliferació de treballs dedicats a estudiar els vincles entre traducció i franquisme a la creació i consolidació de les facultats i departaments de traducció i interpretació del país com a centres d'investigació especialitzada pel que fa als àmbits de la traductologia i dels estudis de recepció literària. El rotund apuntalament actual d'aquests estudis a casa nostra ha discorregut de manera parallela al procés de consolidació que la traductologia ha experimentat a tot el món des de les darreres dècades del segle xx. Reconeguts definitivament com a disciplina acadèmica autònoma, els estudis de traducció s'han anant diversificant molt al llarg de la seva breu existència en àrees de recerca específiques i ben delimitades, per bé que han seguit mantenint estrets lligams i concomitàncies amb els estudis de filologia, lingüística i estudis literaris i culturals, en els quals tenen l'origen. Pel que fa al present estudi, un dels camps de recerca en què la traductologia s'ha manifestat més fecunda ha estat en l'anàlisi dels processos de traducció i recepció literàries des d'un enfocament sociològic i ideològic, i també cultural. En aquest sentit, aquesta disciplina brinda 
una perspectiva i un instrumentari nous al coneixement profund de l'activitat literària duta a terme durant l'etapa franquista.

És justament la pruïja per la claredat en el coneixement del paper desenvolupat per la cultura durant el període franquista el que comparteixen a casa nostra els estudis de traducció amb altres disciplines acadèmiques que parteixen d'una òptica històrica. La reticència a acceptar descripcions excessivament esquemàtiques d'aquest passat; la lluita contra la relativització de la transcendència que tingué en els processos creatius la manca de llibertat que caracteritzà el franquisme i que va condicionar tota activitat artística i intellectual; la descoberta i l'accés a noves dades, com per exemple a la documentació conservada a l'Arxiu General de l'Administració (AGA) d'Alcalá de Henares, i la necessària reinterpretació de les dades conegudes a partir de les noves troballes són alguns dels elements que expliquen la revifalla de l'interès acadèmic per aquest període històric.

Tornant als estudis de traducció, la publicació l'any 2012 de La traducció catalana sota el franquisme, de Montserrat Bacardí, significa un punt d'inflexió important en l'evolució de la recerca en aquest àmbit. Efectivament, aquest volum conté en l'estudi introductori el primer treball monogràfic amb voluntat globalitzadora fet a casa nostra en què l'anàlisi de l'activitat traductora catalana durant el franquisme constitueix l'eix articulador i el nucli temàtic central del discurs. Tots els aspectes que s'hi tracten, alguns de gran calat i importància més enllà del món de la traducció, i que tot seguit enumero, reben atenció en la mesura que són significatius a l'hora d'analitzar el tema principal: el paper del món editorial en l'articulació de la producció cultural; els efectes que hi té la censura i l'autocensura; l'activitat cultural en la clandestinitat i a l'exili; el debat al voltant dels models de llengua literària, i els traductors i la crítica de traduccions. En aquesta obra, dividida en els epígrafs Traduir en silenci (1939-1962) i Traduir de viva veu (1962-1975) en allusió a la permissivitat practicada per les instàncies oficials pel que fa a la publicació de traduccions al català, Bacardí ofereix, com veurem més endavant amb més detall, una radiografia completa, concisa i essencial de tots els aspectes relacionables amb la qüestió, acompanyada d'una bibliografia general de consulta ineludible. El volum proporciona tot seguit una generosa selec- 
ció de textos contemporanis representatius dels diferents aspectes analitzats, escrits per un bon nombre de traductors, editors i crítics que protagonitzaren aquella etapa històrica.

Seguint l'exemple de Bacardí, en el present estudi bibliogràfic em limitaré a ressenyar aquelles publicacions en què l'anàlisi de l'activitat traductora catalana durant el franquisme i/o els aspectes que s'hi relacionen més estretament ocupin un lloc prominent. És obvi que aquesta qüestió afecta, ni que sigui de biaix, qualsevol investigació dedicada a la història literària catalana d'aquest període, però no pretenc oferir aquí un estudi exhaustiu que reculli tots els treballs en què se'n faci esment - una pretensió que probablement seria impossible de respectar-; més aviat voldria oferir una eina útil i pràctica que serveixi d'orientació a aquells que vulguin endinsar-se en el tema. Convé en primer lloc, doncs, que assenyali els treballs que constitueixen els precedents de la recerca actual, que dugueren a terme la ingent tasca d'esbrossar camins $i$ als quals devem en gran part el fet que les investigacions posteriors hagin estat possibles com ho han estat. Tot seguit abordaré els articles i estudis que van començar a sovintejar a partir de mitjans de la dècada dels anys noranta del segle passat, en bona mesura sota l'auspici i l'empara de les facultats de traducció. Comentarem a continuació el procés de consolidació d'iniciatives de recerca que tingué lloc durant la primera dècada del nou segle i que va acabar quallant en la creació de grups d'investigació estables i en una recerca focalitzada específicament, ara sí, en l'estudi dels vincles entre traducció i franquisme.

Cal dir que d'ençà de la publicació de l'estudi de Montserrat Bacardí, la bibliografia apareguda al voltant del tema «franquisme i traducció» no ha parat de créixer, com veurem, i tot fa pensar que les línies de recerca que s'han anat obrint aquests darrers anys ofereixen un llarg recorregut del qual esperem uns fruits que ens enriqueixin en el coneixement d'aquest període decisiu de la nostra història literària i cultural. Parallelament a les investigacions dutes a terme en l'àmbit català, els estudis dedicats al franquisme i a la traducció també viuen a la resta d'Espanya un moment d'ebullició. M'hi referiré en la mesura que aquests treballs constitueixin una contribució al coneixement de la qüestió a casa nostra. En darrer lloc, partint del mateix principi de rellevància, em referiré puntu- 
alment a alguns treballs que analitzen la qüestió des d'una òptica internacional i comparativa, com per exemple el manual Translation Under Fascism, editat l'any 2010 per Christopher Rundle i Kate Sturge.

En l'apartat de conclusions voldria oferir una diagnosi personal de futur per a la recerca en el nostre àmbit: què queda per fer i quines vies cal que seguim. Ens hi ajudarà, per començar, el coneixement de les publicacions que tenen previst sortir a la llum aviat.

\section{Precedents}

En primer lloc, doncs, tractaré de les obres que constitueixen un referent bàsic per als estudiosos de la història de la traducció catalana durant el franquisme, pioneres en certa manera en els estudis de traducció sense que sigui possible encabir-les en aquesta disciplina. Són estudis que analitzen aspectes essencials de la producció cultural i literària d'aquest període en què la traducció, com sabem, tingué un paper rellevant. Els autors de les dues primeres obres (Cisquella, Sorolla i Erviti, d'una banda, i Abellán, de l'altra) estan vinculats a disciplines acadèmiques que cal qualificar d'emergents en l'Espanya dels anys seixanta, setanta i vuitanta: el periodisme i la sociologia, respectivament. La resta d'autors (Gallofré, Hurtley, Orduña) procedeixen del món de la filologia i els seus treballs són representatius de la renovació d'enfocaments metodològics que experimentà aquesta disciplina a les acaballes del franquisme, amb la incorporació de perspectives com la sociològica i la de la teoria de la recepció, entre d'altres.

\section{La censura}

Les primeres obres que parlen dels vincles entre traducció i franquisme s'ocupen, sobretot, dels efectes de la censura institucional en la publicació de llibres, tot i que des d'una òptica traductològica la qüestió només hi és estudiada encara de manera molt parcial. Per començar, hem de fer esment de treballs que tracten del fenomen de la censura en l'àmbit espanyol i que en la seva anàlisi consideren també la producció de llibres catalans. L'estudi de la censura franquista d'autors i obres estrangers ha 
anat creixent incessablement des de l'aparició d'aquestes primeres obres i en certa manera s'ha establert com a disciplina autònoma, tant en l'àmbit espanyol com en el català. La indubtable sortida a la llum de nous documents vinculats a aquest camp, com també la continuada vigència de l'enfocament sociològic i la consideració del factor ideològic en els estudis de traducció auguren continuïtat en la recerca del paper desenvolupat per la censura en l'activitat traductora.

Només dos anys després de la mort del dictador, l'any 1977, i quan la censura encara continuava exercint plenament les seves funcions, Georgina Cisquella, José Luis Erviti i José Sorolla publicaven La represión cultural en el franquismo. Diez años de censura de libros durante la Ley de Prensa (1966-1976), una tesi de llicenciatura que, per l'interès i l'actualitat que té, fou difosa conjuntament per un bon grapat d'editorials que havien estat especialment afectades per l'acció de la censura. L'obra analitza les conseqüències que tingué per a les cases editorials l'aprovació, l'any 1966, de la llei de premsa, l'anomenada llei Fraga — promulgada aparentment per liberalitzar l'edició a Espanya-, i s'atura a descriure les ambigüitats del seu article segon. En aquest famós article es confirmava la derogació de la censura prèvia obligatòria, que passava a tenir caràcter voluntari, però l'Estat es reservava la capacitat d'actuació a tots els efectes en cas que les obres publicades i distribuïdes atemptessin greument contra els principis del règim. Aquesta disposició de coses, en realitat, no era res més que un intent de rentat d'imatge i al mateix temps d'homologació internacional de la legislació espanyola. En la pràctica, però, va fer augmentar la pressió exercida sobre els editors en la tria i supervisió de les obres a publicar per tal d'evitar les segures accions i sancions governamentals posteriors. L'estudi de Cisquella, Sorolla i Erviti inclou, a més, una descripció succinta dels diferents agents que integraren l'aparell de censura: des dels responsables polítics amb noms i cognoms fins als censuradors anònims. Els tres autors del treball recullen també algunes de les claus que definiren l'acció de la censura: els temes i els autors «maleïts» pel règim; el tractament que reberen les anomenades llengües regionals; l'especial duresa amb què fou tractada la literatura catalana, i l'autocensura com a efecte «collateral» en l'activitat creadora. Finalment, el llibre conté un interessant apèndix en què s’ofereixen llistes, classificades 
per editorials, dels llibres i de les publicacions —originals o traduïtsque, tot i la suposada magnanimitat de la nova llei, foren segrestats per l'Administració, d'aquells que foren desaconsellats als editors, de les obres que sofriren silenci administratiu, dels llibres que foren publicats amb supressions i d'aquells als quals es denegà la importació.

El 1980 sortia a llum una obra de Manuel L. Abellán que amb el temps ha esdevingut un clàssic de referència obligada, Censura y creación literaria en España (1939-1976), un llibre que planteja ja les qüestions fonamentals per a la recerca posterior. L'estudi d'Abellán comença amb la descripció de la gènesi formal de la censura franquista l'any 1938, tot distingint el tractament legal dispensat per als diferents gèneres i àmbits d'aplicació, una qüestió en absolut menor. Així, doncs, Abellán repassa a continuació les disposicions de la censura aplicada a llibres i revistes, al cinema, al teatre, als espectacles i actes públics, i finalment a la premsa i les publicacions periòdiques. En la segona part, l'autor ofereix una radiografia dels efectes de la censura en la creació, a partir d'una enquesta feta als escriptors espanyols l'any 1974, i recull les possibilitats efectives de publicació que aquests tingueren, incloses les edicions que es feren fora d'Espanya i les obres que restaren inèdites. Tot seguit tracta dels criteris aplicats genèricament pels censors i en detalla una descripció del perfil professional i intellectual. En la tercera part de l'obra, Abellán fa un repàs cronològic, any per any, començant el 1939 i acabant l'any 1976, de les directrius i dels criteris d'actuació aplicats per la censura en cada moment, així com dels condicionaments sociopolítics que n'expliquen les variacions; l'autor també fa un repàs de les principals efemèrides de l'acció de la censura en la producció literària d'expressió castellana.

El 1989, el mateix Abellán publicava en la Revista de Catalunya l'article «Apunts sobre la censura literària a Catalunya durant el franquisme». L'autor reclamava als investigadors catalans més atenció a un fenomen - la censura - que havia condicionat de manera brutal la creació literària a Catalunya. En aquest treball, en què ja fa allusió a l'estudi que aleshores encara estava en curs de Maria Josepa Gallofré, Abellán utilitza algunes dades del seu estudi previ, tot especificant-ne l'abast per al cas català. En aquestes pàgines, l'autor dedica una atenció especial a les relacions que Manuel de Pedrolo mantingué amb la censura i el pren com a 
exemple d'escriptor insubornable que en cap moment deixà que condicionessin la seva activitat creadora.

Una tercera obra de referència obligada, d'aparició una mica més tardana i que cal considerar com el precedent més directe dels estudis actuals en aquest camp a casa nostra, és L'edició catalana i la censura franquista (1939-1951), de Maria Josepa Gallofré, publicada l'any 1991. Es tracta del primer treball monogràfic dedicat a la censura del llibre català i, per tant, del primer que incideix en els seus problemes específics, com també en la particular transcendència que el fenomen de la censura tingué globalment per al sistema literari català. L'anàlisi que Gallofré fa de la producció editorial catalana en la primera postguerra es restringeix al tractament que l'oficialitat dispensà a les iniciatives legals de publicació en català, i deixa de banda l'edició en clandestinitat o a l'exili. Pel que fa a les traduccions descriu, doncs, els tortuosos camins seguits per les sollicituds d'edició de la Bíblia catalana i d'alguns clàssics de la Fundació Bernat Metge, possibles gràcies a la intercessió de personatges influents com Francesc Cambó i Joan Estelrich durant la primeríssima postguerra, així com de les edicions de bibliòfil i de tiratge molt restringit d'algunes obres clàssiques, com ara la Divina Comèdia i El paradís perdut; també hi destaca la tenacitat $\mathrm{i}$ insistència en aquest sentit d'editors com Cruzet $\mathrm{i}$ Arimany. Al llarg de l'escrit, Gallofré posa en relleu la manifesta voluntat del règim, executada a través de l'aparell de la censura, d'evitar que el llibre català reconstruís ponts amb el seu públic natural, sobretot a través de traduccions d'obres d'autors contemporanis i en edicions de caràcter popular. L'autora assenyala reiteradament, doncs, l'objectiu governamental exprés de vetar la publicació de traduccions al català.

Les tres obres esmentades s'ocupen dels efectes de la censura en la producció editorial espanyola i catalana; en cap d'aquests estudis la consideració dels efectes de la censura en la importació de llibres estrangers ocupa un lloc central, però totes tres en fan esment i en destaquen la transcendència. Per a la investigació posterior la importància d'aquests treballs rau, a banda de la seva oportunitat històrica i de la seva lucidesa analítica, en el fet d'haver fixat amb rigor les directrius d'una recerca de base documental amb una voluntat exhaustiva. 


\section{Món editorial}

L'any 1986 feia aparició l'estudi de Jacqueline Hurtley, basat en la seva tesi doctoral, Josep Janés. El combat per la cultura, i dedicat a un dels editors més importants de la Barcelona de preguerra, en català, i de la primera postguerra, en castellà. Pel que fa a les relacions entre traducció i franquisme, aquesta obra, tal com destaca Jordi Castellanos en el pròleg, té la virtut, entre altres coses, d'assenyalar «la importància que pot arribar a tenir l'editor en l'organització de la vida cultural i literària». I en relació amb Janés, la importància rau, entre altres coses, en l'habilitat que tingué per posar en circulació en l'Espanya de la postguerra un nombre importantíssim de traduccions, especialment de literatura anglesa, que significaren una finestra oberta a l'exterior i un contrapès molt notable a la cultura impulsada pel règim. L'anàlisi que Hurtley fa dels catàlegs i de les obres publicades per Janés durant el franquisme posa de manifest fins a quin punt l'editor prosseguí el seu projecte cultural iniciat en català durant la República, que no excloïa de cap manera la dimensió comercial del llibre.

Un altre aspecte important que destaca Hurtley de l'acció de Janés en la postguerra és la manera com «assistí» un bon nombre d'escriptors, traductors i gent de lletres que passaven penúries econòmiques i dificultats per trobar feina en el nou context polític - els proporcionava encàrrecs que els alleugerissin la seva situació, molt sovint encàrrecs de traducció. Un aspecte més que l'estudi de Hurtley té l'encert d'assenyalar és la importància que durant el franquisme tingueren les institucions culturals estrangeres, sovint amb seu i representació oficial a Madrid i a Barcelona, com a finestres d'entrada d'idees i aires nous. Hurtley se centra en el paper que Walter Starkie desenvolupà a Espanya a través del British Council, i en connivència amb Josep Janés, per facilitar la traducció i l'edició d'uns quants autors contemporanis en llengua anglesa.

Un any després de l'aparició de la monografia de Hurtley, Edicions 62 editava, amb motiu del 25è aniversari de la seva fundació, el volum que duia per títol Edicions 62: vint-i-cinc anys (1962-1987), el qual anava precedit pel text introductori del seu editor literari, Josep Maria Castellet, «Memòries poc formals d'un editor literari». Amb aquest escrit, tal com 
veurem més endavant, inaugurava per al món de l'edició catalana de la postguerra - Carlos Barral ja ho havia fet prèviament en castellà- una tradició que continuarien altres editors i que seria una aportació valuosíssima al coneixement d'aquest període, tot i no estar subjecta als paràmetres de la recerca acadèmica. Per a l'investigador, aquests relats de primera mà constitueixen, tenint en compte la importància de la traducció per a les editorials catalanes i sobretot per a Edicions 62, un material de recerca de primer ordre.

\section{Estudis de recepció}

Un estudi també pioner pel que fa als estudis de traducció i recepció literàries durant el franquisme, basat en la recepció de teatre contemporani estranger, és el treball de Javier Orduña El teatre alemany contemporani a l'Estat espanyol fins el 1975, publicat l'any 1988. Es tracta d'una obra que s'afegeix a la important recerca duta a terme aleshores a Catalunya al voltant de l'activitat teatral durant l'època franquista i que també preveia aspectes de recepció (GALLÉN 1982, 1985), centrada del tot en el cas d'Orduña i a analitzar la presència en l'escena espanyola i catalana d'obres d'autors alemanys contemporanis. D'acord amb els paradigmes d'anàlisi proporcionats per la literatura comparada i la teoria de la recepció literària, Orduña fa un seguiment exhaustiu de les diverses vies de penetració d'unes propostes de renovació teatral que exerciren una influència determinant en l'evolució del teatre català en un context clarament advers als discursos crítics i trencadors. No cal dir que el treball s'ha de vincular, per bé que no exclusivament, amb la influència que tingué l'obra de Bertolt Brecht a Catalunya a través de figures com Ricard Salvat i Feliu Formosa.

Convé en aquest punt fer un breu aclariment conceptual pel que fa a les diferents accepcions del terme recepció tal com s'empra en les disciplines que s'ocupen de la història literària i cultural. Usat inicialment en la sociologia de la literatura per descriure el paper del lector i l'audiència en la construcció del significat de l'obra literària, en la literatura comparada s'ha fet servir més aviat per designar els fluxos d'idees estètiques i motius literaris que tenen lloc entre diferents tradicions literàries i culturals, partint de la comparació. Pel que fa a la traductologia, el mateix 
terme sembla que s'ha especialitzat a descriure el procés d'incorporació a un determinat sistema literari d'obres i autors forans per mitjà de la traducció. Si bé al començament d'aquest treball destacàvem el procés d'emancipació dels estudis de traducció en relació amb les disciplines en què tenen l'origen, ara cal que recordem que sovintegen els casos en què les línies entre unes i altres disciplines són difoses i difícils d'escatir: pensem en la diferència que hi entre l'anàlisi de la recepció de Sartre a Catalunya, d'una banda, i la de la recepció de l'existencialisme en la literatura catalana, de l'altra. Per posar-ne un exemple.

\section{El camí cap a la recerca actual}

Sense cap mena de dubte, tal com apuntàvem en començar, cal relacionar el creixement i la consolidació a casa nostra de la recerca en els àmbits de la traducció i la recepció literàries amb la creació de facultats i departaments de traducció i interpretació, i, per tant, amb l'homologació acadèmica d'aquests estudis a qualsevol altra disciplina universitària. El 1992, l'antiga Escola Universitària de Traducció i Interpretació de la UAB (EUTI) esdevenia la primera facultat de traducció d'Espanya i, poc després, el mateix any, obria les portes la Facultat de Traducció de la UPF; el 1993 iniciava l'activitat acadèmica la Facultat de Traducció de la Universitat de Vic, i amb posterioritat, el 1994, s'inauguraren els departaments de traducció de les universitats de Castelló (Jaume I) i Alacant. Una mica més endavant, la Universitat de València incorporà aquesta disciplina als plans d'estudi de la Facultat de Filologia. A banda d'aquest fet decisiu, una altra de les eines que contribuí a consolidar la recerca en l'àmbit de què tractem fou la revista universitària Quaderns. Revista de Traducció, que l'any 1998 inicià la seva activitat de publicació i que ha mantingut ininterrompudament fins al present. En certa manera, Quaderns és la continuació d'una revista que, vinculada a l'EUTI, havia nascut el $1982 \mathrm{amb}$ el nom de Cuadernos de traducción e interpretación/Quaderns de traducció $i$ interpretació, la primera publicació periòdica especialitzada en aquestes disciplines que s'editava a l'Estat, i que es publicà fins al 1992. Una de les conseqüències de l'aparició de totes aquestes noves institucions i plataformes és la presa de consciència en el món acadèmic de la importància 
central que l'activitat traductora ha tingut modernament en l'articulació del sistema literari català.

Durant la darrera dècada del segle passat i els primers deu anys de l'actual, s'anà intensificant amb nous mitjans i plataformes la recerca centrada a estudiar l'activitat traductora duta a terme en el període franquista, per bé que alguns treballs de referència que tot seguit comentarem parteixin encara de marcs històrics i conceptuals més amplis. Als enfocaments de recerca assenyalats en el primer punt, se n'hi afegiren d'altres. D'entrada cal destacar els estudis que analitzen els models de llengua literària emprats en les traduccions fetes durant el franquisme; després, l'increment d'estudis que tractaven de la recepció durant aquest període d'autors procedents d'altres tradicions literàries (sobretot dels vinculats a corrents de tall realista, i en particular del neorealisme italià o l'existencialisme francès). Una tercera línia d'investigació que també prengué volada aquells anys fou l'anàlisi històrica de la reflexió traductològica i de la crítica de traduccions fetes a casa nostra. Finalment, cal consignar els treballs dedicats a la descripció de la tasca de traductors que, en circumstàncies molt diverses, dugueren a terme la seva activitat durant l'etapa franquista (Carme Serrallonga, Xavier Benguerel, Jordi Arbonès, Maria Aurèlia Capmany, Manuel de Pedrolo, entre d'altres). Una conseqüència «collateral» de tota aquesta sacsejada, finalment, és la progressiva integració de l'òptica traductològica en els estudis filològics d'historiografia literària catalana, sobretot pel que fa a la influència d'altres literatures i tradicions en la configuració del propi sistema literari. I, en no menor proporció, cal consignar l'augment de l'interès en la resta de departaments de filologia de les nostres universitats per estudiar fenòmens de recepció literària associats a les respectives tradicions literàries: d'autors i obres procedents de la literatura francesa, italiana, alemanya, americana, anglesa, polonesa, russa, etc.

\section{Models de llengua en les traduccions}

L’any 1993, en el marc de les Jornades d'Estudi Catalanes organitzades pel Departament d'Hispàniques, tingueren lloc a la Universitat de Manchester diverses ponències sobre el tema «La traducció i la literatura catalana 
des del 1400 fins al present». Joan Sellent hi participà amb la contribució «La traducció literària en català al segle xx: alguns títols representatius», en la qual tractava del pes i de la influència del model dellengua literària forjat sota els auspicis del Noucentisme i la seva vigència en les traduccions catalanes posteriors. Sellent, a banda de repassar críticament la tasca traductora personalíssima d'escriptors com Josep Carner, Josep M. de Sagarra i Carles Riba, es fixava en l'hegemonia duradora del model de prosa noucentista, usada «acríticament» i de forma històricament desplaçada en la majoria de traduccions catalanes fetes amb posterioritat, $\mathrm{i}$ sobretot durant el tardofranquisme, pràctica afavorida per les circumstàncies adverses en què es produí la literatura catalana en aquest període. L'autor destacava l'artificialitat d'aquest model fora del context històric en què havia nascut i el progressiu enquistament que va patir com a referència inqüestionable per a bona part dels traductors. Amb tot, Sellent citava en el seu breu estudi alguns traductors que aconseguien escapar-se de la tendència general: Salvador Oliva, Joaquim Mallafrè, Gabriel Ferrater. La contribució de Joan Sellent en aquelles jornades, revisada, no sortí a llum en forma d'article fins al 1998 a Quaderns, de manera que el seu impacte, tenint en compte que es referia a qüestions «espinoses» que semblaven assumides tàcitament i amb més o menys resignació per part de tothom, fou molt restringit a l'inici.

En canvi, hi hagué un treball que adoptà igualment un punt de vista molt crític pel que fa al model de llengua literària vigent $i$ a la seva gènesi i que aconseguí provocar un rebombori considerable: el llibre de Xavier Pericay i Ferran Toutain, El malentès del noucentisme, publicat l'any 1996 amb el subtítol «Tradició i plagi a la prosa catalana moderna». L'estudi d'ambdós filòlegs parteix d'una minuciosa descripció del lent i tortuós procés de gestació d'un model reeixit de llengua literària catalana des de la Renaixença fins a les acaballes del primer terç del segle xx. Els autors destaquen la decisiva intervenció d'escriptors, d'intellectuals i de polítics noucentistes en la fixació de la llengua, que discorregué parallela a la normativització, i subratllen el fet que aquests tingueren a disposició els instruments polítics necessaris per fer-la efectiva gràcies a la constitució de la Mancomunitat de Catalunya l'any 1914. Pericay i Toutain ressalten el paper clau que els noucentistes atribuïren en aquest procés a les 
traduccions, especialment de narrativa, en tant que laboratori d'experimentació lingüística ideal, exempt dels perills que la llengua real presentava com a base natural dels gèneres narratius, ateses les seves impureses idiomàtiques. En l'ambient de plena ebullició de l'activitat literària que visqué Catalunya els anys vint i trenta, els autors remarquen aleshores la transcendència del tall que representà la irrupció de la dictadura franquista en l'evolució natural que havia emprès la producció cultural i, parallelament, la consolidació de la llengua literària a casa nostra. Pel que fa als nostres objectius, del llibre de Toutain i Pericay interessen sobretot els capítols finals. Hi analitzen de quina manera, al seu parer, en la represa de l'edició en català al començament de la dècada dels anys seixanta s'imposà categòricament el model de prosa noucentista més artificiós com a patró exclusiu de prosa literària catalana a seguir, especialment gràcies a l'assumpció compartida —exigida o imposada-, que aquell era l'únic model que respectava del tot la idiosincràsia de la llengua catalana i en servava la correcció, uns aspectes obsessius en aquells temps de prohibició. Segons els autors, una bona part de la producció de traduccions feta durant la segona meitat del segle xx, i també de la producció original d'escriptors, es féu sota l'influx d'aquella prosa postnoucentista, encarcarada i artificial.

El cavall de batalla de Toutain i Pericay en la crítica que fan al model de llengua literària impulsat a Catalunya dels anys seixanta ençà, sempre segons les seves línies d'argumentació, és la importància decisiva que tingueren i continuen tenint en la seva configuració criteris de naturalesa extraliterària i marcadament ideològica. Així, doncs, el principi de la desitjable elaboració d'un registre literari inspirat en els usos reals i naturals de la llengua és substituï, en el cas de la llengua catalana, per la «censura» i pel control exercit per gramàtics i correctors, que no s'atura en la modificació de les «impureses» de la producció literària d'altri, sinó que acaba convertint-se en el paradigma que segueixen escriptors i traductors. L'anàlisi de l'abast del paper que han tingut els correctors en la fixació del model de llengua literària dels anys seixanta ençà és un aspecte que, tot i que s'esmenta sovint, està pendent d'un tractament sistemàtic i aprofundit en la recerca. 
És veritat que algunes reaccions a l'aparició d'El malentès del noucentisme (PARRA 1998 i MALLAFRÈ 2000) en criticaren un cert maniqueisme, una simplificació innegable i deliberada a no basar l'anàlisi de l'activitat traductora de la postguerra ençà en un «corpus» prou ampli i significatiu de traduccions i traductors, i el fet de prendre exclusivament com a llengua de referència vàlida el barceloní. No deixa de ser menys cert, tanmateix, que la crítica ferotge expressada en aquesta obra obrí un debat fructífer que posava damunt la taula una qüestió que, atesa la realitat sociolingüística contemporània del català i la seva situació política en tot el domini lingüístic, era difícil de tractar. Sense cap mena de dubte, l'òptica de Pericay i Toutain enriquí els estudis de traducció literària a Catalunya i la seva anàlisi continua essent de referència per a qualsevol estudiós que s'ocupi d'aquest període (MARCO 2000).

L'anàlisi i el debat al voltant dels models de llengua emprats en les traduccions són, en el cas de les traduccions catalanes, temes recurrents i d'una gran centralitat en els estudis de traducció a casa nostra, especialment si comparem el pes de la seva consideració amb el que s'esdevé, en aquest sentit, en tradicions literàries en què la qüestió lingüística està més desvinculada del debat ideològic, cultural i fins i tot polític. No en va, en l'apartat següent, dedicat a resseguir la reflexió traductològica i la crítica de traduccions fetes pels nostres escriptors, traductors i crítics, la qüestió de la llengua segueix ocupant una part important del discurs teòric.

\section{Teoria i crítica de traduccions}

Pel caràcter pioner que té, tot i que només molt puntualment vinculat a l'estudi del període en qüestió, cal citar ara una obra de referència obligada; una obra que ens permet confirmar la progressiva importància que els estudis de traducció adquiriren al nostre territori durant la dècada dels noranta del segle passat, per bé que en aquest cas cal destacar el caràcter individual de la iniciativa. Es tracta del primer tractat d'història i de reflexió traductològica publicat a casa nostra: Llengua de tribu i llengua de polis: bases d'una traducció literària, de Joaquim Mallafrè (1991), basat en la tesi doctoral que l'autor defensà l'any 1988. L'escrit ofereix en primer lloc una perspectiva històrica de l'evolució d'aquesta FRANQUISME \& TRANSICIÓ 4 (2016) ISSN 2014-511X PUNCTUM, UNIVERSITAT OBERTA DE CATALUNYA \& FUNDACIÓ CARLES PI I SUNYER 
disciplina i constitueix en segon lloc una reflexió sobre l'origen, la naturalesa i les bases de la llengua literària, reflectida en els reptes que planteja al traductor l'exercici de la traducció, sobretot en el cas de la traducció a una llengua com la catalana. La via de reflexió teòrica que s'iniciava amb Mallafrè es veié aviat reforçada per la collecció «Biblioteca de Traducció i Interpretació», d'Eumo Editorial, que inclou manuals de referència imprescindible per a la traductologia feta a casa nostra.

En aquesta collecció, l'any 1998 Montserrat Bacardí, Joan Fontcuberta i Francesc Parcerisas editaven l'antologia de textos Cent anys de traducció al català. Aquest recull de textos escrits entre els anys 1891 i 1990 depassa àmpliament per tots dos extrems les dates que tenim en compte en aquest estudi, però dedica un espai molt significatiu als treballs elaborats i publicats durant el franquisme. En definitiva, el volum representa el primer treball de compilació de textos teòrics i de crítiques de traducció fets a casa nostra que ens permet resseguir les vies de reflexió traductològica obertes pels nostres escriptors, traductors, filòlegs i crítics des del final del segle xIx fins a l'actualitat, propiciades sens dubte per l'exercici d'una activitat que, com dèiem, d'ençà del Modernisme ha articulat de manera molt central la producció literària catalana. Pel que fa a traducció i franquisme, en aquest volum hi ha treballs que, ordenats cronològicament, van des de «De l'art de traduir» de Josep Carner, de l'any 1944, fins a «Sobre traducció de poesia» d'Antoni Pous, escrit el 1974 i publicat el 1976. Es tracta d'una selecció generosa d'articles, pròlegs i treballs d'importància fonamental per a l'estudiós de la traducció catalana del període. S'hi recullen textos d'orientació filològica, especialment els dedicats a les traduccions de clàssics de tots els temps; escrits que plantegen les dificultats amb què toparen els traductors de poesia, molts d'ells també poetes, i, finalment, textos en què s'expressen les inquietuds i les problemàtiques generades per l'activitat traductora duta a terme en aquests anys difícils, que de cap manera es poden desvincular del marc general de la producció cultural catalana contemporània. El caràcter reivindicatiu o programàtic d'alguns d'aquests escrits posa encara més de manifest, si convé, l'absència en el sistema literari català d'espais de debat estètic i ideològic, i en aquest sentit ens ofereix una imatge fidedigna del moment en què 
foren redactats. De seguida parlarem dels estudis dedicats a la crítica literària d'actualitat feta durant el franquisme.

Encara de l'any 1998 és el treball «Joan Sales i els criteris de traducció» (BACARDÍ 1998a, 1998b), que se centra en l'anàlisi dels criteris de traducció emprats per l'editor Sales en la collecció «El Club dels Novellistes», iniciada el 1955. Aquest breu estudi no deixa de constituir una anàlisi de la reflexió traductològica feta per l'editor abans de triar les obres que es plantejava traduir i els criteris que emprava en l'exercici de la traducció.

La crítica de traduccions apareguda en la premsa especialitzada durant el franquisme ha estat analitzada en estudis posteriors - com vèiem, en tant que expressió de les idees sobre traducció debatudes a Catalunya en aquests anys - i també en estudis de recepció d'autors o obres concrets. Finalment cal destacar sobretot els estudis que analitzen el paper que tingueren dues publicacions cabdals en la història de la cultura catalana contemporània, també pel que fa a la crítica de traduccions i l'anàlisi de la recepció a Catalunya d'altres literatures. D'una banda, Serra d'Or, que, en tant que revista de caràcter religiós vinculada a l'Abadia de Montserrat, aconseguí esquivar la prohibició de publicar que afectava la premsa periòdica en català; de l'altra, Destino, una revista d'expressió castellana editada a Barcelona que, tot i estar molt vinculada al règim els primers anys de la dictadura, a poc a poc s'anà convertint en vehicle d'expressió d'una intellectualitat barcelonina belligerant amb el franquisme i en la qual la producció cultural i literària catalana, també la traduïda, trobà un ressò i un seguiment continuats. Ambdues revistes han estat objecte de nombrosos estudis monogràfics. Especialment Destino i el seu editor Josep Vergés, en les obres de Josep M. Huertas i Carles Geli (1990), Isabel de Cabo (2000), Josep C. Vergés (2007) i Ramon Civit Llort (2012). Però també la revista Serra d'Or en el monogràfic que li dedicà Carme Ferré Pavia (2001). Molt recentment, Alberto Cabello Hernández (2015) ha publicat un treball sobre la revista Tele/eXprés. Tots aquests estudis incideixen d'una manera especial a destacar el paper que desenvoluparen les publicacions esmentades com a agents de renovació i resistència cultural durant el franquisme, i és en aquest sentit que tenen cabuda en el present estudi. Els seus autors descriuen minuciosament de quina manera aquestes revistes estigueren pendents de les 
traduccions i les novetats editorials vinculades a les últimes tendències de la literatura contemporània que es publicaven a casa nostra. Sovint, com es destaca en aquests estudis, les obres traduïdes i els seus autors es convertien a les pàgines d'aquestes revistes en motius de controvèrsia entre els nostres escriptors i crítics, que encetaven així algunes escletxes de debat estètic i ideològic.

\section{Traductors. Recepció literària}

Cadascun dels onze números de la revista Quaderns de traducció i interpretació (1982-1992) incloïa en una secció fixa una entrevista a alguna figura vinculada als estudis i/o a la pràctica de la traducció (la revista Quaderns, a partir del 1998, també farà ús d'aquest format). A tall de repàs biogràfic i incidint en la dimensió més pràctica de la traducció literària, hi figuren les entrevistes a dos traductors de gran rellevància en el panorama de la traducció catalana de la postguerra: Carme Serrallonga (núm. 5/6,1985) i Xavier Benguerel (núm. 11/12, 1992). Lourdes Mañé, acompanyada en l'entrevista a Serrallonga per María Dolores Herrera, hi fa un repàs dels respectius periples vitals, de la formació acadèmica i de la intensa activitat que dugueren a terme totes dues figures com a traductors durant el franquisme. Cal considerar aquestes entrevistes gèrmens de posteriors estudis dedicats a aquests i a altres traductors actius en aquest període. En el cas de Serrallonga, a més, Ricard Salvat dedicà unes pàgines prèvies a l'entrevista a fer una presentació laudatòria de la figura i l'exemple de la traductora i pedagoga, responsable, entre altres coses, de la introducció d'importants veus foranes en el panorama literari català. Ja a Quaderns. Revista de Traducció es recuperarà a partir del 1998 el format de l'entrevista per continuar parlant de l'activitat d'alguns dels traductors més prolífics del panorama català, entre els quals hi havia nombrosos traductors molt actius durant el franquisme: Avellí Artís Gener (Botey 2001), Josep Vallverdú (CRIS MORA 2002), Jordi Arbonès (PIJOAN 2003) o Ramon Folch i Camarasa (Lladó, 2004). Al costat d'aquestes entrevistes començaran a aparèixer també, no només a Quaderns, estudis dedicats a glossar l'activitat d'aquests traductors pioners: Francesc Payarols (ESTELRICH 1998) — per bé que l'activitat de Payarols fou gaire- 
bé simbòlica durant el franquisme-, Marià Villangómez (PARCERISAS 1998) i Segimon Serrallonga (FARRÉS 2000). A partir del 2004, com veurem en el proper apartat, la revisió de la tasca duta a terme per alguns d'aquests traductors constituirà un dels eixos primordials de les jornades sobre traducció i literatura que la càtedra Jordi Arbonès, de la Facultat de Traducció i d'Interpretació de la UAB, organitza bianualment.

Pel que fa als estudis dedicats a analitzar processos concrets de recepció literària, cal citar l'exemple pioner de Jaume Tur, que l'any 1974 s'ocupava de la recepció de Goethe a Catalunya a través de les traduccions del Faust a càrrec de Joan Maragall. Pel que fa a l'anàlisi de processos de recepció literària clau que van tenir lloc durant l'etapa franquista, en un sentit comparatista cal citar com a rellevants els treballs de Joan Lluís Marfany $(1977,1988)$; aquest autor tracta de la influència dels corrents realistes espanyols en alguns dels escriptors catalans que iniciaren l'activitat literària en plena dictadura franquista. En aquest cas ens mouríem clarament en el terreny de la comparació de sistemes literaris, i concretament de les relacions especials entre el sistema literari català i l'espanyol. Amb la consolidació dels estudis de traducció a Catalunya, tanmateix, cal consignar un augment progressiu de treballs que s'ocupen d'estudiar diferents aspectes dels processos de recepció de literatura estrangera a casa nostra, en tant que agents de renovació i modernització del sistema literari català.

Si la influència dels corrents realistes de la literatura occidental en la producció de la literatura catalana sota el franquisme ha estat la línia de recerca dominant en els estudis de recepció literària fets a Catalunya, potser la influència del neorealisme italià ha estat la que ha rebut una atenció més primerenca i més continuada. Per exemple, Gabriella Gavagnin (2002) s'interessava per les primeres traduccions de novella realista italiana fetes a Catalunya dins el volum d'Assumpció Bernal i Carme Gregori Realisme i compromís en la narrativa de la postguerra europea. L'any 2003, Vicent Simbor escrivia l'estudi «La recepció del neorealisme italià» i més endavant El realisme compromès en la narrativa catalana de postguerra (2005), en què parlava també d'aquesta influència. Aquestes mostres serveixen per illustrar que les línies que separen els estudis traductològics de recepció literària dels que neixen de la literatura comparada són de 
vegades molt primes i que es tracta, en un bon nombre de casos, d'estudis complementaris.

Una altra línia d'investigació de processos de recepció, de naturalesa més heterogènia i més basada en la necessitat inicial de fer inventari, és la que obria l'any 2004 el dossier publicat a Quaderns, dedicat a la recepció de les literatures eslaves a casa nostra i en el qual l'anàlisi de la recepció d'aquestes literatures durant el franquisme també hi troba el seu espai. Una mica més tard, l'any 2007, amb motiu de la presència de la cultura catalana com a convidada d'honor a la Fira del Llibre de Frankfurt, l'Institut Ramon Llull publicà els dos volums de Carrers de frontera, a cura de Simona Škrabec i Arnau Pons, centrats en les relacions i els fluxos culturals existents entre l'àmbit cultural alemany i el català, i en els quals la recepció de literatura i d'autors d'expressió alemanya durant el franquisme tenen un lloc destacat.

D'altra banda, es desvincula d'aquestes línies de treball l'estudi comparatiu que Rosa Flotats publicà el 1996, basat en la seva tesi doctoral, sobre les relacions entre Paradise Lost, de John Milton, i la traducció catalana que en féu durant el primer franquisme Josep M. Boix i Selva, El paradís perdut. A partir de la comparació textual i filològica del poema original i el traduït, l'autora estableix parallelismes i afinitats estètiques en les poètiques de l'autor i el traductor.

\section{El món editorial}

En la fase que anomenem de consolidació dels estudis de traducció a casa nostra, l'atenció que els estudiosos dedicaren a l'activitat editorial duta a terme durant el franquisme també s'incrementà. L'any 1996, Pilar Puimedon defensava una tesi sobre l'obra de Joan Sales, Joan Sales. La responsabilitat del supervivent, en la qual dedicava un capítol sencer a la seva tasca com a editor. Puimedon hi destacava el desig expressat per Sales reiteradament que la literatura catalana avancés pel camí de la modernització com a única via per a la seva supervivència, i remarcava la inclusió en el catàleg del Club Editor d'una colla de traduccions de narrativa contemporània, pioneres aquells anys en el panorama català, que havien de marcar el camí als creadors catalans i al mateix temps educar el públic lector. 
El 2002, Xavier Moret publicava Tiempo de editores. Historia de la edición en España, 1939-1975, una representació força panoràmica del món de l'edició espanyola durant el franquisme; l'obra dedica una atenció especial a Barcelona com a capital internacional de l'edició en castellà i inclou un repàs succint de l'edició en català a partir de la dècada dels anys seixanta. En ambdós casos, Moret té un interès especial pel paper d'una bona part dels editors catalans - tant si publicaven en castellà com en català com a agents de la renovació literària a Espanya i a Catalunya que es va dur a terme en aquells anys. Hi destaca l'actitud majoritàriament dissident en relació amb el règim franquista, la inquietud intellectual, el contacte constant amb els principals editors europeus i amb la literatura occidental estrictament contemporània, i la seva voluntat d'introduirne les veus principals mitjançant traduccions. Moret retrata sobretot les figures de Josep Janés, Carlos Barral, Josep Maria Castellet, Carmen Balcells, Jorge Herralde i José Manuel Lara.

L'any 2004, Dolors Marín i Agnès Ramírez publicaren Editorial Nova Terra 1958-1978. Un referent. Aquesta obra fa el repàs històric d'una editorial emblemàtica i molt representativa d'una època — el segon franquisme- en què les reivindicacions d'alguns dels sectors socials més marginats pel règim franquista - per motius polítics i culturals obviscomençaren a trobar vies d'expressió. Les autores destaquen la vinculació d'aquesta editorial amb el món obrer i enllacen el seu naixement amb l'antic afany de la classe obrera de proveir-se d'instruments de formació i de creació d'opinió que donessin resposta a les seves necessitats i inquietuds. L'editorial Nova Terra s'especialitzà en llibres relacionats sobretot amb temàtiques socials, polítiques i pedagògiques, i només puntualment publicà literatura (en alguns casos, literatura traduïda). Per mitjà de traduccions, fou la responsable d'introduir a casa nostra algunes de les obres clau de la cultura i el pensament contemporanis.

El 2006, Manuel Llanas publicava L'edició a Catalunya: el segle xx (1939-1975), cinquè volum de la sèrie que Llanas ha dedicat a la història de l'edició a Catalunya del segle xv ençà i que va culminar el 2007 amb el volum sobre els darrers trenta anys del segle xx. A través de la descripció de l'activitat de diferents editorials i editors catalans en el període assenyalat — tant en català com en castellà, i tant pel que fa als àmbits de la 
creació literària com pel que fa als àmbits del coneixement i de la divulgació-, Llanas també mostrava aquí el seu interès per l'activitat traductora duta a terme a Catalunya en el franquisme, que fou molt intensa en un bon nombre de cases editorials. L'obra de Llanas és un instrument imprescindible per guiar-nos en una època que, si bé en els primers anys visqué moments crítics, a partir del final de la dècada dels cinquanta cal qualificar d'edat d'or de l'edició a Catalunya.

Sense moure'ns d'aquest món, i seguint l'exemple de Josep Maria Castellet amb motiu de la celebració del vint-i-cinquè aniversari d'Edicions 62, encara cal fer referència a un tipus de publicació que, tot i no ser estrictament acadèmica, constitueix una font de consulta obligatòria per als estudiosos: es tracta de les memòries d'editors o d'intellectuals vinculats al terreny de l'edició. En aquest sentit disposem a casa nostra d'un bon exemple de textos que, sens dubte, ens ajuden a reconstruir des del relat de l'experiència personal el període de què parlem, especialment pel que fa a la descripció dels contactes amb els editors estrangers, les iniciatives de traducció i les traves amb la censura i l'Administració. A partir, doncs, del camí encetat amb «Memòries poc formals d'un editor literari» (1987), el mateix Castellet escriví l'any 1988 Els escenaris de la memòria i, molt més tard, el 2012, Memòries confidencials d'un editor, de manera que continuava una tradició que Carlos Barral, en castellà, inicià l'any 1975 i que seguiren altres editors o intellectuals vinculats amb l'edició, com ara Miquel Arimany (1993) i Joan Gomis (1994), Jorge Herralde (2001), Rafael Borràs (2003, 2005) i Esther Tusquets (2005), entre d'altres.

Aquestes memòries, a banda de l'interès que indubtablement desperten el testimoniatge directe i la dimensió humana dels fets narrats, ens forneixen sovint de dades que serien introbables en cap altre tipus d'estudi de caràcter acadèmic i, per tant, constitueixen per a l'investigador una font d'informació de gran valor. Alguns d'aquests textos, com hem vist, precedeixen, a tall d'introducció, volums editats per commemorar algun aniversari o efemèride celebrada per l'editorial en qüestió. Els volums commemoratius solen incloure, a més, un breu repàs històric de l'editorial, els avatars que han acompanyat el seu periple vital, com també els seus catàlegs actualitzats fins a la data commemorativa, de manera que esdevenen una font d'obtenció de dades molt important per a l'invesFRANQUISME \& TRANSICIÓ 4 (2016) ISSN 2014-511X PUNCTUM, UNIVERSITAT OBERTA DE CATALUNYA \& FUNDACIÓ CARLES PII SUNYER 
tigador: 50 anys, Edicions Proa: 1928-1978 (1979); Proa 75 anys a tot vent: 1928-2003 (2003); Edicions 62: mil llibres en català (1962-1979) (1979); Edicions 62: vint-i-cinc anys (1962-1987) (1987); Edicions 62: catàleg general 1962-2011: [50 anys] (2012). En aquest sentit, aquestes obres són les primeres fonts a testimoniar no tan sols l'auge de traduccions que experimentà l'edició catalana els anys seixanta, sinó també la crisi d'edició i de saturació de traduccions que s'experimentà en el mercat català al final dels anys seixanta i començament dels setanta.

\section{Els grups de recerca actual. El GETCC, el TRILCAT i el GETLIHC}

La recerca actual al voltant de l'activitat traductora a Catalunya durant el franquisme, com apuntàvem al principi, està marcada per l'existència de grups d'investigació consolidats vinculats a tres universitats catalanes - la UAB, la UPF i la UVic - els quals dediquen una atenció especial a aquesta temàtica. Així, doncs, la bibliografia actual, per bé que no exclusivament, està lligada a l'activitat d'aquests grups i a la dels membres que en formen part, sigui collectivament o individualment. L'organització de jornades dedicades a aspectes diversos relacionats amb el tema de què tractem, la participació collectiva o individual del grup en congressos nacionals o internacionals que parlen de la nostra temàtica, l'edició conjunta de monografies i treballs, i la contribució individual a altres publicacions, constitueixen la seva activitat principal. Tal vegada una de les característiques que cal destacar de la tasca d'aquests grups és la continuada i estreta collaboració mútua que els distingeix.

Si bé cal datar el reconeixement ministerial dels grups de recerca actuals cap al final de la primera dècada d'aquest nou segle, els seus membres, sobretot els investigadors principals, parteixen d'una llarga experiència investigadora en la temàtica de què ens ocupem, duta a terme individualment o de manera collectiva en grups de recerca anteriors. Així, doncs, avui dia aquesta recerca fóra impensable, per exemple, sense l'existència prèvia dels tres projectes que esmento a continuació, tots distingits amb el reconeixement ministerial corresponent: Las ideas literarias en Cataluña durante los siglos $X I X$ y $X X$, un treball dut a terme entre els anys 1993 i 1996 amb Joaquim Molas (Universitat de Barcelona) com 
a investigador principal; Literatura y Traducción en la España del siglo XX (1994-1997), encapçalat per Ángel Crespo (Universitat Pompeu Fabra), i Materials sobre traducció i recepció de les literatures estrangeres en la cultura catalana (1995-1996), per Enric Gallén (Universitat Pompeu Fabra). En aquest sentit també és d'obligació parlar de la tasca feta, des de l'any 1996, pel Grup d'Estudis de Literatura Catalana Contemporània sota la direcció del malaurat Jordi Castellanos Vila, en el qual han participat un bon nombre d'investigadors que integren els nous grups de recerca.

Els àmbits de recerca vigents en l'actualitat representen força la continuació de les vies obertes en el passat per tots els precedents que hem anat veient, però també cal consignar l'obertura de noves línies d'investigació. Abans de parlar de la recerca que emprenen avui dia els diferents grups esmentats cal que ens referim, ni que sigui de manera succinta, a l'obra de Montserrat Bacardí La traducció catalana sota el franquisme. Com dèiem al començament, la publicació el 2012 d'aquest estudi representa un punt d'inflexió en el nostre àmbit de recerca: pel caràcter de compendi i per la fixació d'àrees de recerca ben delimitades. En primer lloc, cal entendre'l com a crònica històrica que presenta amb ordre i de manera exhaustiva els fets i les circumstàncies que acompanyaren l'activitat traductora a Catalunya entre el 1939 i el 1975, i que l'autora agrupa en dues fases diferenciades: Traduir en silenci (1939-1962) i Traduir de viva veu (1962-1975).

Bacardí ens ofereix en la primera part una descripció del desolat panorama dels anys inicials de la postguerra; pel que fa a l'activitat traductora al català, estava caracteritzat majoritàriament per la impossibilitat de publicació. A desgrat d'això, i en parallel a l'emmudiment definitiu o al salt al castellà d'un bon nombre de professionals de la traducció i l'edició catalanes d'abans de la guerra, l'autora consigna la manutenció d'una mínima activitat en aquests anys, centrada en les iniciatives clandestines de traducció, en les publicacions literàries illegals i absolutament minoritàries que incloïen en les seves pàgines textos traduïts, així com en les edicions de bibliòfil i d'algunes reedicions i edicions de clàssics, totes les obres amb tirades reduïdíssimes, que obtingueren ja a finals dels anys quaranta l'autorització per ser publicades. Bacardí descriu aleshores la lenta progressió en l'obtenció, per part dels editors, de permisos de publi- 
cació de traduccions al català al llarg dels cinquanta, i tracta de dos àmbits de l'activitat cultural i editorial en què, donada la seva idiosincràsia, la traducció al català aconseguí obrir una escletxa: el llibre religiós i l'escena teatral — aquesta darrera deslligada de l'àmbit editorial.

En la segona part de l'estudi, l'autora aborda els canvis polítics i legals que tingueren lloc en el si del franquisme i que propiciaren un canvi de paradigma pel que fa a la política del llibre, una situació que tingué com a conseqüència l'esclat editorial del llibre català, especialment pel que fa a la publicació de traduccions. Bacardí descriu les diferents iniciatives editorials empreses durant aquests anys, centrades sobretot en narrativa i assaig i, en menor proporció, en poesia i teatre. També destaca la importància del llibre de temàtica religiosa, així com la florida de les publicacions de literatura infantil, que en gran manera es forniren de traduccions.

Al costat del repàs històric de les iniciatives de traducció i de les traduccions fetes durant el franquisme a Catalunya, l'estudi de Bacardí exposa alguns dels temes clau que determinaren l'activitat traductora catalana en aquest període: la censura i l'autocensura com a xacres coercitives en l'activitat editora i en la creació; la formació dels traductors i la seva professionalització durant el període esmentat de florida editorial; el debat al voltant dels models de llengua literària en temps d'irrupció de nous corrents literaris renovadors i amb una llengua bandejada de les institucions i dels principals mitjans de comunicació; la reflexió traductològica i els termes en què es produí a casa nostra, i, finalment, la crítica literària i de traduccions. Bacardí es fa ressò dels treballs escrits sobre aquestes qüestions i n'ofereix una anàlisi, no extensiva però sí de gran profunditat, que obre les portes a posteriors estudis en els diferents camps.

Centrem-nos, ara sí, en els grups de recerca actuals, i en especial en la dimensió bibliogràfica de la seva activitat. Voldria tornar a insistir en el fet que les activitats de recerca i les publicacions de cadascun d'aquests grups disposen sempre d'una nodrida presència de collaboracions procedents de membres dels altres dos grups. Cal remarcar que aquesta realitat, sens dubte, afavoreix, reforça i enriqueix la recerca. 


\section{GETCC (Grup d'Estudi de la Traducció Catalana Contemporània)}

L'any 2003, a la Facultat de Traducció i d'Interpretació de la UAB es va crear la càtedra Jordi Arbonès, destinada a gestionar el llegat del traductor i a promoure la investigació al voltant de la traducció en l'àmbit de la literatura catalana. Aquesta càtedra, de tipus honorífic i gestionada per una comissió, va ser l'encarregada d'endegar ja el 2004 les primeres Jornades sobre Traducció i Literatura de la Càtedra Jordi Arbonès, dedicades a aquest traductor i que dugueren per nom «Traduir de lluny: el llegat de Jordi Arbonès». Les contribucions a aquelles jornades, agrupades en un dossier, quedaren recollides en el número 12 de la revista Quaderns (2005). Els treballs publicats, alguns dels quals foren escrits per collegues d'Arbonès que hi tingueren un tracte estret (Joaquim Carbó, Dolors Udina, Alba Pijoan, Ramon Farrés, Victòria Alsina, Marcos Rodríguez i Matthew Tree), tracten de les diverses facetes de la seva producció —en tant que traductor, activista cultural a l'exili i teòric de la traducció- i volen ser un homenatge a una figura emblemàtica de la traducció a casa nostra.

Després d'aquelles primeres jornades, la Càtedra Arbonès ha continuat organitzant fins a l'actualitat, amb una periodicitat bianual, actes dedicats a aspectes diferents de la traducció contemporània a Catalunya i, especialment, als traductors. Des del 2009 -data del reconeixement del GETCC per l'AGAUR —, les jornades s'organitzen en collaboració amb aquest grup de recerca. Per exemple, l'any 2006 es dedicaren a M. Aurèlia Capmany i Manuel de Pedrolo. Les ponències presentades en aquella ocasió quedaven recollides en el número 14 de Quaderns (2007), en el dossier «Traduir contra el franquisme: Maria Aurèlia Capmany i Manuel de Pedrolo». A banda de l'atenció que la majoria d'investigadors (Carme Arenas, Carles Biosca, Francesc Parcerisas, Judit Fontcuberta, Alba Pijoan i Ricard Ripoll) destinaven al paper de renovadors culturals de Capmany i Pedrolo en tant que introductors a Catalunya de diverses veus de la narrativa italiana contemporània, en el cas de Capmany, i de la narrativa nord-americana contemporània, en el cas de Pedrolo, Pilar Godayol parlava del vessant feminista de la tasca traductora de Capmany, uns àmbits - traducció i feminisme - que aquesta estudiosa, investigadora principal del grup de Vic, ha continuat vinculant en treballs posteriors 
tot aportant a la traductologia catalana la perspectiva de la crítica feminista i la dels estudis de gènere.

Les Jornades sobre Traducció i Literatura se centraren novament en les edicions del 2010 i 2014 en l'activitat duta a terme per alguns traductors durant el franquisme. En el cas de Joan Sales, tanmateix, les ponències i els posteriors treballs publicats en el número 18 de Quaderns (2011) inclogueren, al costat de l'anàlisi de les traduccions enllestides per l'autor (Joaquim Gestí, Ivan Garcia Sala, Carles Castellanos i Manuel Zabala), un estudi de la seva tasca com a editor (Marta Pasqual) i els textos dedicats a les traduccions d'Incerta glòria al francès, a l'italià, al castellà, a l'anglès i al neerlandès (Xavier Pla, Maria Teresa Cattaneo, Carlos Pujol, Sam Abrams i Adri Boon, respectivament). L’any 2014, les jornades es dedicaren als traductors de teatre Josep M. Poblet i Bonaventura Vallespinosa, vinculats a l'escena teatral barcelonina i reusenca, i els treballs resultants (Jaume Ferrer, Margarida Aritzeta, Marta Giné, Teresa Julio, Pau Joan Hernández, Rossend Arqués, Miquel Edo, Joaquim Sala-Sanahuja i Ramon Lladó), que es publicaren en el número 22 de Quaderns (2015), destaquen la contribució d'aquests traductors a mantenir una mínima presència d'autors internacionals en l'escena teatral catalana durant la postguerra, en especial francesos i italians. Independentment de les jornades, la revista Quaderns ha publicat altres escrits dedicats a la tasca duta a terme per altres traductors catalans durant l'etapa franquista: Rafael Tasis (Coll Vinent 2007), Carme Serrallonga (GODAYOL 2010, JULIÀ 2010) i Gabriel Ferrater (UDINA 2010). Es pot assegurar, doncs, que una de línies d'investigació que fins avui s'ha manifestat més prolífica en l'àmbit que ens ocupa ha estat l'anàlisi de la tasca feta pels traductors durant el franquisme, sobretot pel que fa a la contribució individual com a introductors de determinades veus de la literatura internacional a casa nostra. En aquest sentit, a causa de les enormes mancances del sistema literari català durant la dictadura, és especialment remarcable el paper que hi tingueren moltes iniciatives individuals, incloses les dels traductors - naturalment amb el suport del voluntarisme d'una bona colla d'editors, sense els quals hauria estat impossible endegar la reconstrucció del nostre espai literari.

Però les Jornades sobre Traducció i Literatura, i, per tant, el GETCC, no tan sols han dedicat l'atenció a aquesta temàtica, sinó que han abor- 
dat altres aspectes clau de l'activitat traductora duta a terme durant aquest període històric. L’any 2008 se centraven en la traducció catalana a l'exili, un tema que Montserrat Bacardí desenvolupà extensament en el número 16 de Quaderns (2009) i que va reprendre després a Caplletra i a Els Marges (BACARDí 2015a, 2015b). En el mateix número 16 de Quaderns es recollien les aportacions fetes en les jornades, que novament giraven a l'entorn de la tasca desenvolupada a l'exili per traductors concrets: Anna Murià (Dolors Udina), C. A. Jordana (Maria Campillo), Joan Oliver (Miquel M. Gibert), Xavier Benguerel (Josep Maria Ripoll), Agustí Bartra (Sam Abrams), Ferran Canyameras (Xavier Pla) i Montserrat Abelló (M. Elena Carné, Francesc Parcerisas).

L’any 2012, aquestes jornades estigueren dedicades estrictament als vincles entre traducció i censura, un dels temes principals que marquen ara l'agenda de recerca del GETCC, com també la dels altres dos grups de recerca catalans. En el dossier del número 20 de la revista Quaderns (2013) hi ha la contribució que Francesc Vallverdú féu en aquest sentit sobre la seva experiència a Edicions 62 i la de M. Josepa Gallofré sobre la censura de traduccions en la primera postguerra. Al seu costat trobem treballs que aborden aspectes diferents de les relacions entre traducció i censura: el desglaç de la censura durant els anys seixanta pel que fa a les traduccions (Jordi Cornellà-Detrell); la censura d'obres d'assaig (Mireia Sopena); la censura en traduccions de poesia alemanya (Ramon Farrés) i de narrativa alemanya contemporània (Jordi Jané-Lligé), i la censura en les traduccions teatrals dels cinquanta (Enric Gallén) i en el teatre de bulevard (Eusebi Coromina). Aquest dossier posa de manifest la riquesa de perspectives de recerca que continua oferint l'estudi de les relacions entre traducció i censura, tal com demostren el nombre de publicacions sobre aquesta temàtica de la seva aparició ençà, com seguirem veient.

El 2015, en el colloqui de la North-American Catalan Society celebrat a Barcelona, diversos membres dels grups de recerca GETCC i GETLIHC oferiren conjuntament les taules rodones «Traducció i franquisme». Hi presentaren contribucions de molt diversa naturalesa, que demostren l'ampli espectre d'àmbits d'anàlisi que defineix la recerca actual sobre el tema: la recuperació de traduccions inèdites a Internet (Teresa Iribarren), l'estudi de la distribució i promoció illegal de traduccions durant el 
franquisme (Jordi Cornellà-Detrell), l'estudi de les traduccions de la mítica collecció «Bernat Metge» (Montserrat Franquesa) i, fins i tot, treballs que constitueixen una continuació i un aprofundiment en les línies d'investigació ja existents: política i traducció, en l'exemple de Teresa Pàmies (Montserrat Bacardí); l'assaig polític i les traduccions (Pilar Godayol); la censura teatral (Teresa Julio); els models de llengua en les traduccions (Jordi Jané-Lligé), i les traduccions de Carner en la postguerra (Eusebi Coromina). Està previst que els treballs esmentats es publiquin aquest mateix 2016 en un volum coordinat per Montserrat Bacardí i Pilar Godayol.

A banda dels treballs d'edició vinculats al grup, tal com avançàvem, els membres del GETCC han donat a conèixer la tasca de recerca individual en moltes altres publicacions, sovint construint línies d'especialització cada vegada més ben delimitades. Per exemple, Jordi Cornellà-Detrell (2010, 2013a, 2013b, 2016a, 2016b) ha abordat aspectes tan rellevants de la qüestió com la transmissió de l'herència de la censura franquista més enllà dels seus límits històrics a través de la reedició de traduccions, o bé temes relacionats amb la importació i distribució illegal de traduccions durant la dictadura. Mireia Sopena (2006, 2009, 2013, 2015, 2016), gran experta en el món de l'edició durant l'etapa franquista, ha aprofundit en el coneixement individualitzat dels censors, de manera particular en aquells que es dedicaren a la censura d'assaig i en els censors eclesiàstics, i ha obert al públic una faceta de la censura - la de la censura eclesiàstica- gairebé desconeguda del tot fins avui. Montserrat Bacardí (2009b, 2015a, 2015b), com dèiem, ha estat pionera en el tractament de la traducció catalana a l'exili, i, al costat de Pilar Godayol, ha estudiat a fons el paper de les dones en l'activitat traductora catalana (2006, 2013, 2014), i, a més, s'ha ocupat especialment de les traduccions del castellà al català; Carles Biosca (2007, 2011, 2013) ha dedicat la seva atenció a la recepció de les literatures romàniques a casa nostra, sobretot la italiana i la francesa; Jordi Jané-Lligé (2013, 2015a, 2015b, 2016) ha treballat la censura en obres de narrativa des de l'òptica de l'anàlisi textual, i Mercè Altimir (2014) i Jordi Mas (2014a, 2014b) han tractat d'aspectes de la recepció i de la influència a Catalunya de la literatura japonesa, en especial de la poesia, també durant el període franquista. A aquestes activitats del GETCC cal afegir la tasca d'edició de traducció de textos cabdals de la literatura universal, en la collecció «Versions», 
que durant el franquisme no van arribar a sortir a llum. Les traduccions editades fins ara han anat a càrrec de Carles Biosca, Judit Fontcuberta i Dolors Udina.

\section{TRILCAT (Grup d'Estudis de Traducció, Recepció i Literatura Catalana)}

El grup de recerca TRILCAT, vinculat a la UPF, es va constituir com a tal l'any 2009, però les línies d'investigació que formen la seva activitat parteixen de projectes de recerca i grups d'investigació endegats i reconeguts durant la dècada dels noranta del segle passat, en els quals participaren alguns dels membres actuals del grup. Els projectes històricament vinculats a aquest grup, amb Enric Gallén com a investigador principal des de l'any 1995, i alguns dels seus membres s'han centrat en l'estudi dels processos de recepció i traducció a Catalunya del final del segle XIX ençà, i han anat abordant cronològicament les diferents etapes històriques que constitueixen aquest període. Si els primers projectes tractaven de qüestions relacionades amb el flux i l'arribada d'idees estètiques i literàries contemporànies a Catalunya, a partir del 1999 se centraren a resseguir les etapes històriques que emmarquen els processos de recepció i traducció literàries a casa nostra, començant pel període 1906-1939. A partir de l'any 2009, coincidint amb la consolidació com a grup de recerca, i fins al 2014 el TRILCAT centrà els seus projectes d'investigació en l'anàlisi dels processos de recepció i traducció durant l'època franquista.

El 2010, doncs, el grup dedicà el III Simposi sobre Traducció i Recepció en la Literatura Catalana Contemporània al tema «La traducció i el món editorial de postguerra», les ponències del qual foren publicades l'any 2011 en forma de monogràfic amb el mateix títol, La traducció i el món editorial de postguerra. La publicació, que disposà de la contribució d'especialistes de diferents àmbits i de diverses universitats catalanes, inclou una visió panoràmica dels primers anys de la postguerra a càrrec d'Albert Manent, gran especialista de l'edició a Catalunya, i ofereix un panorama molt exhaustiu de l'activitat editorial duta a terme a casa nostra durant els anys de postguerra amb relació a les traduccions. Bona part dels articles d'aquest volum està dedicat a analitzar el paper dels editors en la materialització de les iniciatives de traducció: Joan Sales (Marta Pasqual); 
Aymà i Arimany (Manuel Llanas); Estelrich, i Montaner i Simon (Sílvia Coll-Vinent); la collecció «Isard», de Vergara (Laura Vilardell); Nova Terra (Pere Quer); Cavall Fort (Alba Girons), i Jordi Arbonès a Aymà/Proa (M. Elena Carné). El segon bloc estudia el tractament donat per les editorials a altres tradicions literàries, autors o obres concrets: a les literatures eslaves (Ricard San Vicente, Bożena Zaboklicka, Ivan Garcia Sala); a la literatura alemanya (Jordi Jané-Lligé); a la italiana (Chiara Chieregato, Carles Biosca); a l'obra de Vita Sackville-West (Marta Ortega), i a la primera traducció catalana de l'Ulisses (Teresa Iribarren). En tercer lloc, hi ha dos treballs que aborden la traducció i l'edició d'obres de teatre durant la postguerra (Enric Gallén, Judit Fontcuberta). Finalment trobem un treball dedicat a la revista d'expressió castellana Papeles de Son Armadans i a la seva relació amb la cultura catalana (José Francisco Ruiz Casanova). Aquesta publicació contribueix enormement a conèixer de quina manera els editors catalans es convertiren en els puntals del manteniment $\mathrm{i}$ la recuperació culturals durant el franquisme, sense haver de renunciar mai a l'anhel de modernitat que caracteritza la cultura catalana contemporània, expressat a través del seu interès per les traduccions.

Més indirectament relacionat amb el període de què tractem, però assenyalant vies de recerca incipients per al futur, fou el V Simposi sobre Traducció i Recepció en la Literatura Catalana Contemporània del TRILCAT, celebrat l'any 2013 i dedicat a la «Traducció indirecta en la literatura catalana», les actes del qual es publicaren el 2014 i foren editades per Ivan Garcia Sala, Diana Sanz Roig i Bożena Zaboklicka. Tot i que una bona part dels treballs se centren en traduccions indirectes al català fetes abans de la Guerra Civil Espanyola, també contenen aportacions interessants sobre el que s'esdevingué durant la dictadura franquista en aquest sentit. En són exemples l'article sobre poesia xinesa, de Manel Ollé; el treball sobre les traduccions d'Ibsen, de Carolina Moreno; l'estudi de les traduccions de Sinkiewicz a Catalunya, de Bożena Zaboklicka; el treball d'Ivan Garcia Sala sobre traduccions indirectes del rus al català, i l'article de Jordi Mas i Alba Serra-Vilella sobre traduccions del japonès.

Un dels aspectes que el TRILCAT també ha abordat sistemàticament des de la seva constitució com a grup ha estat el de les relacions contemporànies entre els sistemes literaris català i espanyol. A aquesta temàtiFRANQUISME \& TRANSICIÓ 4 (2016) ISSN 2014-511X PUNCTUM, UNIVERSITAT OBERTA DE CATALUNYA \& FUNDACIÓ CARLES PI I SUNYER 
ca hi ha dedicat tres simposis, les contribucions als quals han quedat recollides en sengles publicacions (2007, 2013 i 2015). En aquests treballs s'analitzen els intercanvis, la recepció i les influències entre ambdós sistemes literaris (incloent-hi, puntualment, referències a la traducció, encara que aquest aspecte hi tingui una rellevància menor), unes qüestions que són d'una importància determinant per al desenvolupament de la cultura catalana modernament. D’especial interès per a aquest estudi és el simposi que el TRILCAT dedicà a la figura de Josep M. Castellet l'any 2014, les contribucions al qual es publicaren el 2015, ja que tracta d'una de les figures clau de l'edició, la crítica i la teoria literària catalana i espanyola contemporànies.

Des del 2011 aquest grup de recerca edita l'Anuari TRILCAT, una publicació dedicada a la traducció i la recepció literàries que inclou nombrosos treballs relacionats amb l'època franquista. Ja en el primer número trobem un article de Jordi Aymà sobre l'editor Aymà, «Jaume Aymà i Mayol», i un treball conjunt d'Ivan Garcia Sala i Ricard San Vicente titulat «Sobre El doctor Jivago i les seves versions». En el número 2 (2012), José Francisco Ruiz Casanova, membre del TRILCAT, va escriure sobre la tasca traductora d'Agustí Bartra tant al català com al castellà, feta majoritàriament a Mèxic. Jordi Cornellà-Detrell hi publicava un article sobre la llarga vida de la censura a través de la reedició de traduccions. En el número 3 (2013), un altre membre del TRILCAT, Miquel M. Gibert, oferia un treball sobre la presència de l'obra de Bernard Shaw a Catalunya durant el franquisme, i Jordi Mas López hi publicava una anàlisi de les diverses traduccions al castellà de les Elegies de Bierville, de Carles Riba. En el número 4 (2014), Marcello Giugliano escrivia l'article «La traducció de poesia com a eina de renovació cultural: reflexions sobre Agustí Bartra i Miquel Desclot traductors». Finalment en el darrer número, el 6 (2015), Joaquim Sala-Sanahuja publicava un estudi sobre l'activitat traductora de Miquel Martí i Pol, i Maria Dasca un treball sobre la recepció de l'obra de John Steinbeck a Espanya.

Amb relació a l'activitat conjunta d'aquest grup, cal destacar l'elaboració d'extenses bases de dades sobre els estudis de traducció i recepció, que es poden consultar en l'enllaç següent: http://trilcat.upf.edu/ recursos/. 
Pel que fa a la recerca individual, cal parar esment en les aportacions d'Enric Gallén, l'investigador principal del grup, centrades en l'estudi de la recepció, traducció i producció teatrals a casa nostra. Els treballs de Gallén sobre les traduccions de teatre durant el franquisme són nombrosos i arrenquen del començament de la seva trajectòria com a investigador $(1982,1985)$, tal com ja hem apuntat. En els darrers anys, tanmateix, ha dedicat una atenció especial a aquest període històric, i ha abocat llum en un terreny que, sovint desvinculat de l'edició, presenta dificultats molt particulars per a la recerca (2011, 2012a, 2012b, 2013a, 2013b, 2013c, 2015a, 2015b, 2015c, 2016). Els aspectes de la traducció teatral que aborda Gallén són diversos i comprenen des de qüestions de censura fins a aspectes de recepció literària o de producció teatral que, sens dubte, constitueixen una base sòlida per a la recerca futura. D’altra banda, l'any 2015, Enric Gallén va coordinar el monogràfic que la revista Represura va dedicar a la censura en la literatura catalana i que incloïa, també, treballs dedicats a la censura d'obres traduïdes: el de Mireia Sopena sobre la censura eclesiàstica, el de Laura Vilardell sobre les traduccions de Camus a la collecció «Isard», i la mateixa aportació de Gallén sobre la censura d'una obra de Michel Duran en traducció de Xavier Regàs. El tractament especial que el concepte de traducció i recepció mereixen en el cas del teatre, com dèiem, en el qual cal incloure les adaptacions al cinema o al teatre de textos narratius, musicacions incloses, ens permeten augurar que aquest serà un dels camps a desenvolupar en el futur de la recerca.

Altres membres del TRILCAT han encetat línies d'investigació noves que són, sens dubte, un enriquiment i un eixamplament de mires per al futur de la recerca. En aquest sentit, Josep Miquel Ramis (2010, 2011, 2012, 2013a, 2013b, 2014) s'ha endinsat en la temàtica de l'autotraducció a partir de l'anàlisi d'aquesta pràctica en l'obra de Sebastià Juan Arbó, des dels anys trenta fins a la mort de l'autor, el 1984. L'aprofundiment en aquest àmbit de recerca no tan sols ens brinda una perspectiva interessant d'anàlisi textual i estilística de parelles d'obres, sinó que contribueix a aprofundir, a partir de la consideració de la trajectòria autotraductora d'un mateix autor, en les relacions entre els sistemes literaris català i espanyol durant el franquisme, i en la manera com condicionaren l'activitat literària d'alguns autors. Com dèiem, es tracta d'un camp de recer- 
ca prometedor, com també testimonia el manual editat per Enric Gallén, Francisco Lafarga i Luis Pegenaute, Traducción y autotraducción entre las literatures ibéricas (2010). Una altra membre del grup, Caterina Briguglia (2012, 2013a, 2013b), ha abordat el tractament del dialecte en algunes traduccions al català d'obres italianes durant el franquisme. I Chiara Chieregato $(2011,2013)$ s'ha dedicat a analitzar qüestions de la recepció de literatura italiana a casa nostra. Maria Dasca s'ha fixat en la recepció de la literatura nord-americana a Catalunya durant el franquisme (2012, 2015a, 2015b) i molt especialment en el paper decisiu desenvolupat per l'Institut d'Estudis Nord-Americans en la difusió de la seva a casa nostra.

\section{GETLIHC (Grup d'Estudis de Gènere: Traducció, Literatura, Història i Comunicació)}

El grup GETLIHC, vinculat a la Facultat de Traducció de la Universitat de Vic-Universitat Central de Catalunya, es va crear el 1999 i va consolidar-se com a grup de recerca l'any 2014. Tal com indica el seu nom, la seva recerca en el camp de la literatura i la traducció s'ha enfocat des de l'inici des de l'òptica dels estudis de gènere. En els darrers anys, els seus membres han dedicat una atenció especial a la traducció catalana durant el franquisme, sobretot a la censura de traduccions. Fruit d'aquest interès, l'any 2013 es va fer a la Universitat de Vic un seminari dedicat a la «Traducció i censura durant la dictadura franquista», en el qual van participar membres d'altres grups de recerca catalans. Les ponències d'aquella jornada han aparegut recentment publicades en el volum Traducció $i$ franquisme (2016), editat per Laura Vilardell. El volum, prologat per Josep Massot i Muntaner i que s'enceta amb una contribució seva sobre els efectes de la censura en les Publicacions de l'Abadia de Montserrat, reuneix les aportacions d'alguns especialistes del tema que ja hem anat coneixent. Pel que fa a la Universitat de Vic, Pilar Godayol, investigadora principal del grup, hi fa una aportació sobre la censura en les traduccions catalanes de Simone de Beauvoir; Eusebi Coromina i Montse Caralt publiquen sengles treballs sobre les revistes literàries vigatanes Oriflama i Inquietud i la censura de traduccions, mentre que Laura Vilardell escriu sobre la collecció «Isard» i la censura, i Teresa Julio analitza la censura 
en la traducció catalana de La mort de Danton de Büchner. Al costat d'aquests treballs, Mireia Sopena analitza globalment el fenomen de la censura eclesiàstica en les traduccions; Enric Gallén escriu sobre la difusió i traducció dels textos dramàtics en aquest període; Jordi Jané-Lligé ho fa sobre la censura en la narrativa traduïda els anys seixanta, mentre que Jordi Cornellà-Detrell escriu sobre traducció, censura i mercat del llibre en català durant els anys seixanta, tot destacant la crisi d'edició soferta pel mercat editorial català al final de la mateixa dècada.

La perspectiva de gènere en l'anàlisi de la censura de les traduccions catalanes durant el franquisme domina la recerca de la investigadora principal del grup, Pilar Godayol, com es fa palès en les seves publicacions (2007, 2008, 2013a, 2013b, 2014, 2015, 2016), i constituirà una de les seves línies d'investigació futures, amb publicacions imminents.

$* * *$

Ja avisàvem al començament que la investigació sobre traducció i franquisme està dominada avui dia per l'activitat dels grups de recerca que acabem de descriure, sigui en nom del grup o individualment. Tanmateix, aquesta temàtica és present en els treballs d'altres investigadors, que s'hi acosten des de les respectives parcelles de recerca. Per exemple, Xavier Pla escriví l'any 2009 sobre el paper de Ferran Canyameres en la traducció i difusió de l'obra de Georges Simenon a Catalunya, a través de l'editorial Albor. Jordi Canal i Àlex Martín van publicar l'any 2011 un magnífic retrat d'una collecció emblemàtica de la segona etapa del franquisme en la qual les traduccions tingueren un paper absolutament preponderant: La Cua de Palla: retrat en groc i negre. I el 2013 Josep Mengual publicà un nou acostament biogràfic a l'editor Josep Janés.

En acabar aquest repàs estem segurs de deixar-nos treballs que d'una manera o d'una altra han inclòs la perspectiva traductològica en la seva anàlisi, o escrits que informen sobre algun dels aspectes que hem analitzat aquí. Les característiques d'aquest estudi fan impossible incloure tota la literatura que pugui haver tingut en compte aquesta perspectiva, per la qual cosa demano disculpes d'entrada. 


\section{Traducció i franquisme a Espanya}

L'estudi de les relacions entre traducció i franquisme també han experimentat els darrers decennis a la resta d'Espanya un augment digne de menció, fet que respon a motius similars als que expliquen el seu creixement a casa nostra. Com apuntàvem a l'inici, en aquest treball em referiré bàsicament a aquells estudis sobre la traducció a Espanya durant el franquisme que incloguin referències significatives a l'activitat traductora a Catalunya. Tanmateix, em remetré a altres obres que, sense referir-s'hi en particular, inclouen aportacions que contribueixen a aprofundir en el coneixement del tema a casa nostra.

Pel que fa a publicacions relacionades amb la història de la traducció, Francisco Lafarga i Luis Pegenaute recullen a Història de la traducció a Espanya (2004) un generós apartat dedicat a la història de la traducció en l'àmbit de la cultura catalana. Marcel Ortín és l'autor del capítol sobre les traduccions fetes a Catalunya del Noucentisme ençà, en el qual ofereix una síntesi excellent del paper de la traducció en l'articulació del sistema literari català durant el franquisme.

Potser l'àmbit en què la recerca ha aconseguit avenços més grans a Espanya és en el de l'estudi dels vincles entre la censura i la traducció. En primer lloc cal fer referència a l'activitat i les publicacions del grup TRACE, vinculat des de l'inici (1999) a les universitats de Lleó i el País Basc. Aquest grup, que ha basat la recerca en una anàlisi exhaustiva dels expedients de censura i la documentació conservada a l'AGA, se centra en l'estudi de les traduccions espanyoles censurades, i si hi fem referència és perquè la seva activitat, com la dels membres que el formen, ha estat pionera i exemplar.

En segon lloc cal destacar publicacions i autors que no s'han limitat a estudiar el fenomen de la censura des de la traducció, sinó globalment, però que per això mateix també inclouen aquesta dimensió en les anàlisis. Començarem per la revista digital Represura, dedicada a estudiar les relacions entre la censura i el llibre en totes les seves facetes possibles $i$ que va iniciar l'activitat, de forma pionera, l'any 2006. La revista es publicà en una primera època fins al 2013, i el 2015 encetà la segona etapa, ara ja vinculada a la Universitat d’Alcalá de Henares. En el primer número 
d'aquest segon període inclogué, tal com hem vist, un monogràfic sobre la censura en la literatura catalana, coordinat per Enric Gallén. També hi participà Jordi Cornellà-Detrell (2015) amb un treball en què, a través del cas de les traduccions de James Baldwin a Espanya, tractava de la censura i del contraban editorial.

L'investigador Eduardo Ruiz Bautista, com a coordinador, incloïa en el volum Tiempo de censura (2008) un capítol dedicat a la censura del llibre català, escrit per Antonio César Cantano. Tant en els primers capítols d'aquesta obra com en el seu estudi previ, Los señores del libro: propagandistas, censores y bibliotecarios en el primer franquismo (2005), l'anàlisi que Ruiz Bautista ofereix del paper de la censura en la producció del llibre espanyol constitueix una eina imprescindible per al coneixement d'aquest fenomen. En la mateixa direcció, l'assaig Letricidio español. Censura y novela durante el franquismo (2014), de Fernando Larraz, investigador de la Universitat d'Alcalá de Henares i editor de Represura, brinda, a banda de les dades que aporta, reflexions i punts de vista que convé tenir ben presents.

L’any 2015, Gora Zaragoza, Juan José Martínez i José Javier Ávila-Cabrera publicaren a Quaderns de Filologia de la Universitat de València el volum Traducción y censura. Nuevas perspectivas. La voluntat explícita dels editors era oferir nous horitzons de recerca en l'anàlisi dels vincles entre censura i traducció, tant pel que fa a l'aprofundiment del coneixement de l'etapa franquista - l'àmbit a hores d'ara més conegut - com a l'obertura de la recerca a altres etapes històriques, encara molt poc estudiades. Hi hagué tres investigadors que aportaren la perspectiva catalana a la publicació: Pilar Godayol, amb un treball sobre la censura de les traduccions catalanes de Simone de Beauvoir; Teresa Julio, amb un article sobre la recepció a Espanya i a Catalunya de Dantons Tod, de Büchner, i Jordi Jané-Lligé, amb un estudi sobre el paper dissident, renovador i desafiador dels editors catalans J. Janés, C. Barral i J. M. Castellet davant l'oficialisme cultural franquista.

Pel que fa a l'àmbit editorial, el 2013 l'especialista d'història contemporània de l'edició espanyola, Francisco Rojas Claros, recollia en el volum Dirigismo cultural y disidencia editorial en España (1962-1973) l'anàlisi del paper que van tenir algunes editorial catalanes, al costat d'altres editorials espanyoles, en la renovació estètica i ideològica que es produí en 
l'Espanya franquista a partir dels anys seixanta, sobretot gràcies a la publicació de traduccions. També Jesús A. Martínez Martín (2015) incloïa en la seva Historia de la edición en España 1939-1975 un breu capítol sobre l'edició a Catalunya.

\section{Estudis internacionals}

Pel que fa als estudis internacionals, d'una banda cal distingir aquells treballs que han estudiat globalment les relacions entre censura i traducció en estats dominats per règims feixistes - i que, per tant, s'han ocupat de la traducció en l'Espanya franquista-, i de l'altra, els treballs que els investigadors catalans sobre aquest tema han publicat en mitjans internacionals. Els primers, tot i que no necessàriament recullen la realitat específica de la traducció catalana durant la dictadura franquista, ofereixen descripcions, marcs d'anàlisi i un instrumentari conceptual que poden ser molt útils a l'hora fer avançar la recerca en el nostre àmbit, en especial des d'una òptica comparatista. En aquest sentit, Francesca Billiani edità l'any 2007 el volum Modes of Censorship and Translation: National Contexts and Diverse Media. Hi incloïa un article de Jacqueline Hurtley sobre la resistència editorial en el primer franquisme i la figura de Josep Janés, tot intentant definir un context general d'interpretació del fenomen de la censura a partir del terme textualitat nacional.

L'any 2010, Christopher Sturge i Kate Rundle publicaren Translation under Fascism, en el qual, a més de considerar separadament els casos d'Itàlia, Alemanya, Portugal i Espanya, intentaven trobar punts de concomitància que definissin la política cultural dels règims feixistes amb relació a la importació de béns culturals aliens.

Des d'un altre punt de vista, el 2005 Lawrence Venuti incloïa en el seu article «Local Contingencies: Translation and National Identities», publicat en el volum Nation, Language and the Ethics of Translation, una comparació entre la tasca editora de Josep Carner i de Joan Sales, com a exemples de dues maneres ben diferenciades de dur a terme un projecte de reconstrucció literària d'abast nacional a través de les traduccions.

També voldria remarcar el procés d'internacionalització visible que s'esdevé en la recerca catalana: cada vegada hi ha més investigadors de 
casa nostra que publiquen treballs en revistes i publicacions internacionals. Una mostra en serien les publicacions de Pilar Godayol, que parlen sobretot de traducció, gènere i censura (2013a); les de Cornellà-Detrell (2011), dedicades a la censura i la traducció; les de Montserrat Bacardí (2002, 2005, 2014) sobre les dones catalanes traductores; les de Jordi Jané-Lligé (2010, 2015b), dedicades a l'anàlisi textual de traduccions enllestides durant el franquisme, i les de Josep Miquel Ramis sobre l'autotraducció (2013b).

\section{La recerca del futur: algunes conclusions}

L'estudi bibliogràfic que ara concloem torna a posar de manifest la importància que l'activitat traductora ha tingut a l'hora d'articular la producció literària i cultural contemporània a Catalunya. El règim franquista aconseguí inicialment fer emmudir tota una cultura que se sentia viva i es volia moderna; a partir de la dècada dels anys cinquanta, per sort, la producció cultural catalana s'anà recuperant gradualment, i fou als anys seixanta quan esclatà amb una força i un dinamisme que encara avui ens meravellen. Per als principals activistes culturals de tot aquest fosc període, la traducció no deixà d'ésser mai un dels mitjans cabdals de manutenció de l'activitat cultural, i durant els anys seixanta es convertí programàticament en un dels eixos essencials de renovació estètica i ideològica a casa nostra. Els estudiosos de la traducció catalana s'han encarregat, al llarg de les darreres dècades, de definir bé aquesta realitat i de destacar-ne la transcendència.

Arribats a aquest punt, amb l'objectiu de dirigir la mirada cap endavant, tot seguit m'aventuraré a destacar els trets que, al meu parer, defineixen la recerca actual. Tal vegada els més rellevants són tres: un grau d'especialització elevat, una diversificació creixent i una internacionalització incipient. Pel que fa a l'especialització, d'entrada convé congraciar-se'n i destacar-ne la necessitat: només el treball de detall, la minuciosa tasca documental, permet arribar a un coneixement profund del tema. Ara bé, cal no perdre mai la perspectiva global dels fets ni la correcta apreciació del valor de les dades. En aquest sentit voldria referir-me a dos aspectes de signe oposat presents en la recerca actual a casa nostra. En 
primer lloc, alludiré a l'anàlisi i a la consideració dels expedients de censura que hi ha dipositats a l'AGA, a Alcalá de Henares. Tot i que són documents que ens forneixen una informació molt valuosa al voltant de la història individual de les traduccions, i que constitueixen una manifestació concreta de les directrius fixades per la institució de la censura, no hem de perdre de vista quin és el marc d'interpretació general d'aquests textos, mínima expressió de la política cultural. De vegades, a parer meu, se'n sobredimensiona la significació com a documents demostratius, tot i que en reitero la importància. En segon lloc, i en l'extrem oposat, cal demanar de la recerca, pel que fa a la descripció de les característiques de la llengua de les traduccions fetes durant el franquisme, que es basi escrupolosament en l'anàlisi d'un corpus prou ampli de textos que en justifiqui les conclusions. Si la diagnosi per a un bon nombre de traduccions de l'època ha estat fins ara el domini d'una llengua artificiosa i encarcarada, hereva directa d'un noucentisme dissecat, cal documentar i analitzar també els intents d'actualització de registres i de modernització de la llengua literària duts a terme per traductors de les noves generacions, formades ja literàriament en l'hegemonia dels corrents literaris realistes.

Pel que fa a la diversificació, cal congraciar-se novament del fet que els darrers anys s'han eixamplat a casa nostra les perspectives d'anàlisi en els estudis de traducció. La incorporació de la perspectiva dels estudis de gènere, en aquest sentit, constitueix un enriquiment valuosíssim i estrictament necessari per a la recerca de la traducció durant el franquisme. També cal fer referència a les aportacions recents que aborden la traducció des d'un vessant polític i ideològic, com a expressió dels equilibris de poder existents. En són exemples destacables els estudis sobre la censura eclesiàstica, els relatius al pes de l'assaig en la traducció dels anys seixanta, els que descriuen el paper de les institucions polítiques estrangeres en la divulgació cultural, i els que s'ocupen de les complicades relacions entre el sistema literari català i l'espanyol. En aquest cas cal destacar que la traductologia catalana es va fent ressò, sense cap mena de dubte, de l'evolució general de la traductologia internacional.

Pel que fa a la recerca de la traducció i el franquisme, tal vegada hi ha alguns camps que per la dificultat d'anàlisi han restat fins ara inexplorats, el coneixement dels quals contribuiria, sens dubte, a completar la 
descripció del fenomen de la traducció a Catalunya: es tracta, d'una banda, de l'impacte en el mercat editorial que tingueren les traduccions en el període de què parlem. No tan sols de saber quants exemplars de les traduccions es posaren a la venda, sinó de com es vengueren i qui les comprà. La crisi de l'edició catalana al final dels anys seixanta i la reducció dràstica de l'activitat traductora que tingué com a conseqüència són símptomes evidents de l'excés de traduccions que s'arribaren a publicar aleshores - però segurament, a més, de la manca de preparació del públic català per accedir-hi. Què cal extreure'n, també per al present, d'aquell episodi?

Lligat amb l'impacte de les traduccions, i endinsant-nos en la dimensió comparatística de l'estudi dels processos de recepció, convindria rastrejar també quin fou l'efecte de l'activitat traductora en la producció cultural i literària pròpies. Certament és de difícil mesurabilitat, però sembla que caldria explorar com fructificaren els esforços de renovació estètica i literària que impulsaren editors i traductors durant el franquisme i quins foren els «efectes literaris» de tota aquesta activitat. Relacionat amb això, caldria especificar detalladament quins foren els criteris que guiaren la confecció dels catàlegs editorials a casa nostra, en els quals les traduccions tingueren un paper central: sens dubte, els grans editors europeus i els catàlegs de les cases editorials respectives exerciren una influència decisiva sobre els nostres editors, com també la crítica literària europea, però de ben segur que les modes, els criteris comercials i els gustos personals contribuïren a decidir quins autors s'incorporaven als catàlegs i quins no.

Un altre aspecte que encara no ha rebut una atenció merescuda de la recerca és, com avançàvem, la funció dels correctors editorials en la fixació del model de llengua literària catalana dels seixanta ençà, un tema que requeriria una anàlisi sistemàtica i aprofundida. En aquest sentit també hi ha el paper que va desenvolupar la traducció catalana durant el franquisme a les Balears i al País Valencià, que està a l'espera d'estudis que n'abordin la importància i l'impacte, i que ajudin a definir, si cal plantejar-ho en aquests termes, de quina manera s'ha articulat el sistema literari català entès de forma global des del franquisme ençà, també pel que fa al paper de les traduccions. 
La diversificació i l'especialització, com apuntàvem, són símptomes inequívocs de la bona salut dels estudis sobre traducció i franquisme a Catalunya. Això, tanmateix, no ens ha de fer perdre de vista - tornem a insistir-hi- que la traducció és una manifestació més de la producció cultural d'un país. En aquest cas potser no fóra descabellat reivindicar l'escriptura d'una història de la traducció catalana des de l'inici fins a l'actualitat que abordés aquest fenomen d'una manera global, dotant la recerca d'un marc conceptual i d'una perspectiva d'anàlisi ben amplis.

El darrer aspecte que voldria comentar és el de la incipient internacionalització de la recerca al voltant del franquisme i la traducció a casa nostra. Tant si es tracta d'investigacions i investigadors estrangers que s'interessen pel cas català - encara avui molt poc nombrosos-com d'investigacions i investigadors catalans que aconsegueixen fer aparèixer els seus treballs sobre aquest tema en publicacions internacionals, cal qualificar aquesta incipient internacionalització de gran notícia. Entre altres coses perquè cal considerar la cultura catalana — naturalment també pel que fa a la traducció i el franquisme- com un cas d'una excepcionalitat i d'un interès sociològic, polític, literari, també de tenacitat humana, absolutament únic i —mai millor dit—digne d'estudi.

\section{Bibliografia}

Abellán, Manuel L. 1980. Censura y creación literaria en España (1939-1976).

Barcelona: Península.

_.1989. «Apunts sobre la censura literària a Catalunya». Revista de Catalunya 27: $123-132$.

AвrAms, Sam. 2009. «Quelcom neix en tota mort...». Quaderns. Revista de Traducció 16: $67-73$.

- 2011. «David Sales o Joan Rosenthal». Quaderns. Revista de Traducció 18: 29-34.

Alsina KeIth, Victòria. 2005. «Jordi Arbonès: les traduccions de Jane Austen».

Quaderns. Revista de Traducció 12: 47-58.

Altimir, Mercè. 2014. «La transmissió de l'haiku: d'escriptures i de passos fronterers».

Dins Jordi Mas, L'haiku en llengua catalana, 15-40.

AR BONÈs, Jordi. 1995. «La censura sobre les traduccions a l'època franquista». Revista de Catalunya 97: 87-96.

Arenas, Carme. 2007. «Maria Aurèlia Capmany, introductora a Catalunya de la narrativa italiana». Quaderns. Revista de Traducció 14:19-28.

Arimany, Miquel. 1993. Memòria de mi i de molts altres. Barcelona: Columna. 
Aritzeta, Margarita. 2015. «Poblet i Vallespinosa, el gust i la necessitat». Quaderns 22: 25-41.

ARQuÉs, Rossend. 2015. «Les traduccions teatrals de Vallespinosa». Quaderns. Revista de Traducció 22: 75-94.

AYMÀ, Jordi. 2011. «Jaume Aymà i Mayol». Anuari TRILCAT 1:163-173.

BACARDÍ, Montserrat. 1998a. «Joan Sales i la traducció». Dins Pilar OrERo, ed., Actes del Tercer Congrés Internacional sobre Traducció, 319-326. Bellaterra: Universitat Autònoma de Barcelona.

.1998b. "Joan Sales i els criteris de traducció». Quaderns. Revista de Traducció 1: $27-38$.

. 2002. «Notes about History of Translation to Catalan». Catalan Writing 17-18: $13-99$.

- 2005. «Translation from Spanish into Catalan during the 2oth century: Sketch of a chequered history». Dins Albert BRANCHADELl i Margaret Lovell West, ed., Less translated Languages, 257-268. Amsterdam / Filadèlfia: John Benjamins.

_. 2006a. «Ramon Folch i Camarasa, la dèria de (re)escriure». Dins Doctor Honoris Causa Ramon Folch i Camarasa, 5-11. Bellaterra: Universitat Autònoma de Barcelona. - 2006b. «Anna Murià, traductora (in)visible». Quaderns. Revista de Traducció 13: $77-85$

- 2007. «La traducció del castellà al català: una tradició aleatòria».1611. Revista d'Història de la traducció 1.

- 2008a. «Ramon Xuriguera, traductor». Urc 23: 66-72.

- 2008b. «Traduir durant el franquisme, traduir contra el franquisme». Dins Pons \& ŠCrabec, Camins de frontera, vol. 2, 270-271.

—. 2009a. «La traducció en la narrativa de Ramon Folch i Camarasa».XIVè Colloqui Internacional de Llengua i Literatura Catalanes, 79-86. Barcelona: Publicacions de l'Abadia de Montserrat.

— 2009b. «La traducció catalana a l'exili. Una primera aproximació». Quaderns. Revista de Traducció 16: 9-21.

- 2012a. La traducció catalana sota el franquisme. Quaderns 5. Lleida: Punctum.

- 2012b. «Traducción y dictadura. El caso catalán (1939-1961)». Dins El español frente a los retos del siglo XXI: investigación y enseñanza, 247-251. Moscou: Universitat MGIMO.

- 2013a. «Traduir sota la dictadura franquista, traduir clandestinament: Poesia (1944-1945) i Ariel (1946-1951)». MonTi 5: 241-256.

- 2013b. «Joan Oliver, traductor forçat». Rivista Italiana di Studi Catalani 3: 5-21.

- 2014. "Catalan women translators: an introductory overview». The Translator 20, 2: 144-161.

- 2015a. «L'ofici de traduir a l'exili: flors al pol Nord». Els Marges 106: 56-68.

- 2015b. «Apunts sobre exili, llengua i traducció». Caplletra 58:159-182.

BACARDÍ, Montserrat, i Montserrat CASALS. 2012. Joan Sales i Vallès: literatura i política. Joan Oliver, traductor de contraband i retraductor de circumstàncies. Sabadell: Fundació Bosch i Cardellach. 
Bacardí, Montserrat, Joan Fontcuberta i Francesc Parcerisas, ed. 1998. Cent anys de traducció al català (1881-1990). Antologia. Vic: Eumo Editorial.

BACARDÍ, Montserrat, i Pilar GodAYOL. 2006. Traductores. Vic: Universitat de Vic.

- dir. 2011. Diccionari de la traducció catalana. Vic: Eumo.

- 2013. Les traductores i la tradició. 20 pròlegs dels segle $x x$. Lleida: Punctum.

BARral, Carlos. 2001. Memorias. Barcelona: Península.

BERnAL, Assumpció, i Carme Gregori. 2002. Realisme i compromís en la narrativa de postguerra europea. Barcelona: Publicacions de l’Abadia de Montserrat.

BILLIANI, Francesca. 2007. Modes of censorship and translation: national contexts and diverse media. Manchester: St. Jerome.

BioscA, Carles. 2007. «George Simenon traduït per Maria Aurèlia Capmany». Quaderns. Revista de Traducció 14: 29-38.

— . 2011. «Vasco Pratolini en català. Les traduccions de Maria Aurèlia Capmany a Edicions 62». Dins Coll-Vinent, EISNer \& Gallén, La traducció i el món editorial de postguerra, 125-133.

_ . 2013. «Les traduccions de Ionesco al català». Dins Montserrat BACARDí, Francesc Foguet i Enric GALLÉN, ed., La literatura catalana contemporània: intertextos, influències i relacions, 55-64. Societat Catalana de Llengua i Literatura.

Boon, Adri. 2011. «Incerta glòria (al neerlandès)».Quaderns. Revista de Traducció 18:35-40.

Borràs, Rafael. 2003. La batalla de Waterloo: Memoria de un editor. Barcelona: Ediciones B.

- 2005. La guerra de los planetas. Memorias de un editor. Barcelona: Ediciones B.

Bотеy, Virgínia. 2001. «Entrevista a Avellí Artís Gener». Quaderns. Revista de Traducció 6: $155^{-161 .}$

BRIGUGLIA, Caterina. 2012. «Quan el català es troba amb el friülà: Carles Cardó i Pier Paolo Pasolini».1611. Revista d'Història de la traducció 6.

—.2013a. «Quan el traductor és sobretot un escriptor: el cas de la traducció d'El guepard de Tomasi di Lampedusa». Caplletra 54: 33-49.

—.2013b. Dialecte i traducció literària. L'exemple dels traductors catalans. Vic: Eumo editorial.

CABEllo Hernández, Alberto. 2015. Tele/eXprés, cultura y crítica literaria. Alcalá la Real: Zumaque.

CAmpillo, Maria. 2009. «Cèsar-August Jordana. El món de Joan Ferrer». Quaderns. Revista de Traducció 16: 29-42.

CANAL, Jordi, i Àlex MARTín. 2011. La Cua de Palla: retrat en groc i en negre. Barcelona: Alrevés.

CARNÉ, M. Elena. 2009. «Montserrat Abelló, traductora amb nom propi». Quaderns. Revista de Traducció 16: 91-96.

—. 2011. «Jordi Arbonès, traductor d'Aymà/Proa (1966-1999)». Dins ColL-VINENT, EISNER \& GALLÉN, La traducció $i$ el món editorial de postguerra, 229-242.

Castellet, J. M. 1987. «Memòries confidencials d'un editor literari». Dins Edicions 62, Vint-i-cinc anys (1962-1987), 23-105.

- 2012. Memòries confidencials d'un editor. Barcelona: Edicions 62. 
Castellanos, Carles, i Manuel Zabala. 2011. «La traducció de Lo garrèl de Lois Delluc, de Joan Sales». Quaderns. Revista de Traducció 18: 51-67.

CAStelló, Eloi, i Kálmán FALuba. 2004. «Literatura hongaresa i literatura catalana: coneixement mutu». Quaderns. Revista de Traducció 11: 29-44.

Cattaneo, Mariateresa. 2011. «Vicissituds de la traducció italiana d'Incerta glòria». Quaderns. Revista de Traducció 18: 21-23.

Chieregato, Chiara. 2011. «La traducción de Bontempelli, Papini y Buzzati en el mundo editorial catalán de postguerra». Dins ColL-VINENT, EISNER \& GALLÉN, La traducció $i$ el món editorial de postguerra, 111-124.

_ . 2013. «Cinc poetes italians, Saba, Cardarelli, Ungaretti, Montale, Quasimodo de Tomàs Garcés». Dins M. Àngels VERDAGUER, ed., Traduir els clàssics, antics i moderns, 267-276. Barcelona: Publicacions de l'Abadia de Montserrat.

Cisquella, Georgina et al. 1977. Diez años de represión cultural. La censura de libros durante la Ley de Prensa (1966-1976). Barcelona: Diversos editors.

Civit Llort, Ramon. 2012. «Destino i la cultura catalana a les acaballes del franquisme (1966-1975)». Tesi doctoral, Universitat de Barcelona. http://www.tdx.cat/ handle/10803/104478.

Coll-Vinent, Sílvia. 2007. «Rafael Tasis, traductor i divulgador literari». Quaderns. Revista de Traducció 14: 95-104.

- 2011. «Joan Estelrich i Montaner i Simon». Dins Coll-Vinent, Eisner \& GALlÉn, La traducció i el món editorial de postguerra, 215-228.

Coll-Vinent, Sílvia, Cornelia EISNer i Enric GallÉn, coord. 2011. La traducció i el món editorial de postguerra. Lleida: Punctum / TRILCAT.

CORNELLÀ-DETRELL, Jordi. 2010. «Traducció i censura en la represa cultural dels anys 1960». L’Avenç 359: 44-51.

- 2011. Literature as a Response to Cultural and Political Repression in Franco's Catalonia. Colección Támesis. Serie A, Monografías 295. Woodbridge: Tamesis.

_ . 2013a. «La censura després dels censors: algunes reflexions sobre aspectes no resolts de l'herència cultural del franquisme». Anuari TRILCAT 2: 27-47.

_ 2013b. «L'auge de la traducció en llengua catalana als anys 6o: el desglaç de la censura, el XVI Congreso Internacional de Editores i el problema dels drets d'autor». Quaderns. Revista de Traducció 20: 47-67.

- 2015. «La obra de James Baldwin ante la censura franquista: el contrabando de libros, la conexión latinoamericana y la evolución del mercado del sector editorial peninsular». Dins Represura. Revista de Historia Contemporánea española en torno a la represión y la censura aplicadas al libro 1 (nova època): 32-61. http://www. represura.es/represura_1_nueva_epoca_2015.pdf

_ 2016a. «El terratrèmol de les lletres catalanes: traducció, censura i mercat del llibre en català als anys 60». Dins VILARDELL, Traducció i censura en el franquisme, 97-126.

- 2016b. «Barcelona, la ciutat dels llibres prohibits. Importació, venda i consum de llibres illegals durant el franquisme». Quaderns L’Avenç 419:40-48. 
Coromina, Eusebi. 2013. "Censura de la amoralitat femenina de Senyora ambaixadora. Teatre de bulevard de postguerra de Xavier Regàs».QQuaderns. Revista de Traducció 20: $77-88$.

— 2016. «La revista Oriflama (1961-1977), una altra víctima de la dictadura». Dins VILARDELL, Traducció $i$ censura en el franquisme, 127-134.

Coromina, Eusebi, i Pilar Godayol. 2014. «Miquel Martí i Pol, traducció i censura». Ausa 26, 173: 559-574.

Cris Mora, Anna. 2002. «Entrevista a Josep Vallverdú, traductor». Quaderns. Revista de Traducció 8: 121-131.

DASCA, Maria. 2012. "La recepció de la literatura de la Lost Generation en els anys 40 i 50». Dins Eberhard GEISLER, ed., Literatura catalana del segle $x x$ i de l'actualitat, 1938. Frankfurt: Peter Lang.

— . 2015a. «L'Institut d'Études Nord-Américains de Barcelone, un instrument politico-culturel exceptionnel pendant la dictature franquiste». Congrés Traduction et politique, Universitat de Lieja. http://www.traduction2015.ulg.ac.be/textes.html.

_ 2015b. «La recepción crítica de la obra de John Steinbeck en España (19401964)». Anuari TRILCAT 5: 21-34.

DE CAво, Isabel. 2001. La resistencia cultural bajo el franquismo: en torno a la revista Destino, 1957-1971. Barcelona: Áltera.

EDICIONS 62. 1979. Mil llibres en català. Barcelona: Edicions 62.

- 1987. Vint-i-cinc anys (1962-1987). Barcelona: Edicions 62.

EDo, Miquel. 2015. «Bonaventura Vallespinosa, traductor de Pirandello». Quaderns 22: 95-110.

ESTELRICH, Pilar. 1998. «Francesc Payarols, traductor». Quaderns. Revista de Traducció 1: 135-151.

FARrÉs, Ramon. 2005. «Les traduccions de Jordi Arbonès: una visió de conjunt». Quaderns. Revista de Traducció 12: 41-46.

- 2013. «A la paret, escrit amb guix. Una antologia de poesia alemanya de combat censurada». Quaderns. Revista de Traducció 20: 89-94.

FERré PAVIA, Carme. 200o. Intellectuals i cultura resistents. «Serra d'Or», 1959-1977. Cabrera de Mar: Galerada.

FERRER, Jaume. 2015. «Josep Maria Poblet, comediògraf i traductor de teatre». Quaderns. Revista de Traducció 22: 11-24.

Flotats, Rosa. 1997. John Milton i Josep M. Boix i Selva: estudi comparatiu de la traducció d'un clàssic al català. Bellaterra: Publicacions de la Universitat Autònoma de Barcelona.

FogueT, Francesc. 2015a. «Ricard Salvat, censurat (Salvador Espriu, Bertolt Brecht i Josep Maria Muñoz Pujol». Els Marges 107: 12-31.

- 2015b. «El teatro catalán y la censura franquista. Una muestra de los criterios de censura de textos destinados a la representación (1966-1977)». Represura 1 (nova època):184-216. http://www.represura.es/represura_1_nueva_epoca_2015.pdf.

FontCuberta, Joan. 2007. «Pedrolo i La Cua de Palla». Quaderns. Revista de Traducció 14: 49-55. 
FontCU BERTA, Judit. 2001. «Les traduccions catalanes de Molière». Quaderns. Revista de Traducció 6: 79-105.

- 2011. «Les traduccions catalanes de Molière durant el règim franquista». Dins

COll-Vinent, EISNer \& Gallén, La traducció i el món editorial de postguerra, 159-176.

GALLÉN, Enric. 1982. «Notes sobre la introducció de l'existencialisme. Sartre i el teatre a Barcelona (1948-1950)». Els Marges 26: 120-126.

—.1985. El teatre a la ciutat de Barcelona durant el règim franquista (1939-1954).

Barcelona: Publicacions de l'Institut del Teatre de Barcelona / Edicions 62.

- 2011. «Traduir teatre a la postguerra: El barret de Danton i El sombrero de

Dantón (1964-1968)». Dins COLL-VINENT, EISNER \& GALLÉN, La traducció i el món editorial de postguerra, 141-158.

_. 2012a. «Jean Cocteau a l'escena catalana (1917-1966)». Caplletra 53: 35-64.

. 2012b. «Xavier Regàs, traductor teatral. El cas de Camarada Cupido». Dins José

Luis MARTí Ferriol i Ana MuÑoz MiQuel, ed., Estudios de traducción e Interpretació. Vol 2. Entornos de especialidad, 213-219. Castelló de la Plana: Universitat Jaume I.

- 2013a. «Traduir teatre durant el franquisme. El cas dels "Quaderns de Teatre A.

D. B. (1959-1982)”». Dins Traduir els clàssics, antics i moderns. 327-350. Barcelona:

Publicacions de l'Abadia de Montserrat.

_ 2013b. «Dramaturgs italians en l'escena catalana durant el règim franquista».

Dins Maria Carreras, Núria Puigdevall, Patrizio Rigobon i Valentina Ripa,

ed., Ciutat de l'amor. Scrivere la città, raccontare i sentimenti. CD-ROM. 342 [481]-

356[487]. Alessandria: Edizioni dell'Orso.

—. 2013c. «Traducció i censura teatral sota la fèrula franquista dels anys cinquanta». Quaderns. Revista de Traducció 20: 95-116.

_ 2015a. «La censura franquista y la literatura i cultura en lengua catalana».

Represura 1 (nova època): 62-65. http://www.represura.es/represura_1_nueva_ epoca_2015.pdf.

_. 2015b. «Censura teatral y moral católica a fines de los cincuenta. A propósito de Mon coeur balance, de Michel Duran, traducción de Xavier Regàs». Represura 1 (nova època): 146-183. http://www.represura.es/represura_1_nueva_epoca_2015.pdf.

—. 2015c. «Arnold Wesker a Catalunya (1963-2004)». Dins Actes del Setzè

Colloqui Internacional de Llengua i Literatura Catalanes, vol. 3, 163-177. Barcelona:

Publicacions de l'Abadia de Montserrat.

- 2016. «Traducció i difusió de textos dramàtics en temps de censura i moral de postguerra». Dins VILARDELL, Traducció i censura en el franquisme, 51-74.

Gallén, Enric, Francisco Lafarga i Luis Pegenaute, ed. 2010. Traducción y autotraducción entre las literaturas ibéricas. Berna: Peter Lang.

Gallén, Enric, i José Francisco Ruiz Casanova, ed. 2015. Josep M. Castellet, editor $i$ mediador cultural. Lleida / Barcelona: Punctum / Edicions 62.

GALlOFRÉ, M. Josepa. 1991a. L'edició catalana i la censura franquista (1939-1975).

Barcelona: Publicacions de l'Abadia de Montserrat. 
GALLOFRÉ, M. Josepa. 1991b. «Les “nuevas normes sobre idiomas regionales” i les traduccions durant els anys cinquanta». Els Marges 44: 5-17.

- 2013. Autarquia i localisme: les traduccions a la immediata postguerra. Quaderns. Revista de Traducció 20: 69-75.

GARCIA SALA, Ivan. 2011a. «La traducció d'Els germans Karamàzov de Joan Sales: les notes a peu de pàgina». Quaderns. Revista de Traducció 18: 69-79.

_ 2011b. «Algunes observacions en l'anàlisi comparativa d'Els germans Karamàzov de Joan Sales». Dins COLL-VINENT, EISNER \& GALLÉN, La traducció i el món editorial de postguerra, 39-54.

GarCIA SAla, Ivan, i Ricard SAN VICENTE. 2011. «Sobre El doctor Jivago i les seves versions». Anuari TRILCAT 1: 186-246.

GARCIA SALA, Ivan, Diana SANZ RoIG i Bożena ZABOKLICKA. 2014. La traducció indirecta en la literatura catalana. Lleida: Punctum / TRILCAT.

GAVAGNIN, Gabriella. 2002. «Les primeres traduccions catalanes de novelles realistes italianes». Dins BERNAL \& GREGORI, Realisme i compromís en la narrativa de postguerra europea, 187-211.

Geli, Carles, i Josep M. Huertas. 199o. Les tres vides de Destino. Barcelona: Anagrama.

Gestí, Joaquim. 2011. «Joan Sales, la traducció d’El Crist de nou crucificat, de Nikos Kazantzakis». Quaderns. Revista de Traducció 18: 51-67.

Gibert, Miquel M. 2009. «Els Molière de Joan Oliver». Quaderns. Revista de Traducció 16: 43-53.

- 2013. «Bernard Shaw a Catalunya durant el franquisme (1939-1975)». Anuari TRILCAT 3: 3-38.

Giné, Marta. 2015. "Josep M. Poblet i l'adaptació d'El malalt imaginari, de Molière, i altres vodevils provinents del francès». Quaderns. Revista de Traducció 22: 43-54.

Girons MASOT, Alba. 2011. «Traduir per als més joves: Cavall Fort, porta d'entrada del còmic infantil europeu». Dins Coll-VInent, EISNER \& GALlÉn, La traducció $i$ el món editorial de postguerra, 135-140.

Givgliano, Marcello. 2014. «La traducció de poesia com a eina de renovació cultural: reflexions sobre Agustí Bartra i Miquel Desclot traductors». Anuari TRILCAT 4:3-24.

Godayol, Pilar. 2002. «Maria Aurèlia Capmany, traductora». Dins Montserrat Palau i Raül-David Martínez Gili, ed., Maria Aurèlia Capmany: l'afirmació en la paraula, 195-201. Valls: Cossetània.

- 2007. «Maria Aurèlia Capmany, feminisme i traducció». Quaderns. Revista de Traducció 14: 11-18.

- 2008. «Triplement subalternes». Quaderns. Revista de Traducció 15: 41-50.

- 2010. «Carme Serrallonga, el plaer de traduir». Quaderns. Revista de Traducció 17: $17-23$.

- 2013a. «Censure, féminisme et traduction: Le deuxième sexe de Simone de Beauvoir en catalan». Nouvelles Questions Féministes 32: 74-89. https://doi. org/10.3917/nqf.322.0074.

- 2013b. «Simone de Beauvoir en català». Bulletin Hispanique 115 (2): 669-684.

- 2015. «Simone de Beauvoir bajo la dictadura franquista». Dins Zaragoza, MARTíNEZ \& ÁviLA-CABRERA, ed. «Traducción y censura. Nuevas perspectivas». Quaderns de Filologia, Estudis Literaris 20:17-34. 
GodAYol, Pilar. 2016. «Dos clàssics del feminisme censurats». Dins VILARDELL, Traducció $i$ censura en el franquisme, 143-158.

Gomis, Joan. 1994. Memòries cíviques. Barcelona: La Campana.

Gregori, Alfons. 2002. «Maria Aurèlia Capmany, traductora de novelles en francès». Dins Montserrat Palau i Raül-David Martínez Gili, ed., Maria Aurèlia Capmany: l'afirmació en la paraula, 203-221. Valls: Cossetània.

HernÀndeZ, Pau Joan. 2015. «Poblet adapta Simenon. Una tria ètica». Quaderns. Revista de Traducció 22: 69-73.

Her RALDE, Jorge. 2001. Opiniones mohicanas. Barcelona: Acantilado.

Herrera, María Dolores, i Lourdes MAÑÉ. 1985. «De la traducció teatral. Parlant amb Carme Serrallonga». Quaderns de traducció i interpretació 5/6:159-179.

Hurtley, Jacqueline A. 1986. Josep Janés. El combat per la cultura. Curial: Barcelona.

- 2007. «Tailoring the Tale». Dins Billiani, Modes of censorship and translation: national contexts and diverse media, 61-92.

IRIBARREN DONADEU, Teresa. 2011. «La primera traducció catalana de l'Ulisses (1966) de James Joyce, de Joan Francesc Vidal Jové». Dins Coll-Vinent, EISNER \& GalléN, La traducció i el món editorial de postguerra, 81-94.

JANÉ-LLIGÉ, Jordi. 2010. «Modell für die Analyse von literarischen Texten am Beispiel Die verlorene Ehre der Katharina Blum». Dins Cristina JAR ILlot Rodal, ed., Bestandaufnahme der Germanistik in Spanien, 789-80o. Viena: Peter Lang.

—. 2011. «Heinrich Böll, Günter Grass i Wolfgang Koeppen i el món editorial de postguerra». Dins COLL-VINENT, EISNER \& GALLÉN, La traducció i el món editorial de postguerra, 95-109.

_ 2013. «Narrativa alemanya de postguerra: autors traduïts i censura».Quaderns. Revista de Traducció 20:117-145.

- 2015a. «Traducción, censura y construcción del discurso literario. La labor de los editores J. Janés, C. Barral y J. M. Castellet». Dins Zaragoza, Martínez \& ÁvilaCABrERA, ed. «Traducción y censura. Nuevas perspectivas». Quaderns de Filologia, Estudis Literaris 20: 73-90.

_ 2015b. «Literary Translation and Censorship: A Textual Approach». Dins Anna BąCzkowska, ed., Perspectives on Translation, 235-258. Cambridge: Cambridge Scholars Publishing.

. 2016. «La traducció de narrativa dels anys seixanta i la censura». Dins VILARDELL, Traducció $i$ censura en el franquisme, 75-96.

Julià, Lluïsa. 2010. «Carme Serrallonga (1909-1997). Viure l'ideal». Quaderns. Revista de Traducció 17: 9-15.

Julio, Teresa. 2015a. «Comèdies d'exili: Eduard Borràs i Maruxa Vilalta, traduïts per Josep M. Poblet». Quaderns. Revista de Traducció 22: 55-68.

- 2015b. «Dantons Tod, de Georg Büchner: Traducciones y censura en la España franquista». Dins Zaragoza, MarTínez \& Ávila-CABrera, ed. «Traducción y censura. Nuevas perspectivas». Quaderns de Filologia, Estudis Literaris 20: 91-106.

—. 2016. «La mort de Danton, de Büchner, o l'eficiència de la censura en la traducció de Carme Serrallonga». Dins Vilar deLL, Traducció $i$ censura en el franquisme, 135-142. 
LARRAZ, Fernando. 2014. Letricidio español. Censura y novella durante el franquismo. Gijón: Ediciones Trea.

LÁZARO, Alberto. 2004. «Les traduccions de les literatures ibèriques a Estònia, Letònia i Lituània i les traduccions de les literatures del Bàltic Oriental a l'Estat espanyol». Quaderns. Revista de Traducció 11: 59-87.

LLADó, Ramon. 2004. «Sobre literatura i sobre traduccions. Entrevista amb Ramon Folch i Camarasa». Quaderns. Revista de Traducció 10: 215-222.

- 2015. «La modernitat estètica com a imponderable: Vallespinosa traductor de Cocteau, Ionesco i d'altres contemporanis». Quaderns. Revista de Traducció 22: 123-131.

Llanas, Manuel. 2006. L'edició a Catalunya: el segle xx (1939-1975). Barcelona: Gremi d'Editors de Catalunya.

_ 2011. «Traduir al castellà en un compàs d'espera. Les editorials Aymà i M. Arimany en els anys 40 i 50». Dins Coll-Vinent, EISNer \& Gallén, La traducció $i$ el món editorial de postguerra, 177-214.

MALLAFRÈ, Joaquim. 1991. Llengua de tribu i llengua de polis. Barcelona: Quaderns Crema.

- 2000. «Models de llengua i traducció catalana». Quaderns. Revista de Traducció 5:9-27.

MANENT, Albert. 2011. «Durant un quart de segle les traduccions en català foren prohibides». Dins COLL-VINENT, EISNER \& GALLÉN, La traducció i el món editorial de postguerra, 287-297.

MAÑÉ, Lourdes. 1992. «Entrevista a Xavier Benguerel». Quaderns de traducció $i$ interpretació 11-12: 287-303.

Marco, Josep. 200o. «Funció de les traduccions i models estilístics: el cas de la traducció al català al segle XX». Quaderns. Revista de Traducció 5: 29-44.

MARFANY, Joan Lluís. 1976. «Notes sobre la novella espanyola de postguerra». Els Marges 6: $29-57$.

Martínez Martín, Jesús. 2015. Historia de la edición en España, 1939-1975. Madrid: Marcial Pons.

MAs LóPEZ, Jordi. 2013. «Les traduccions al castellà de les Elegies de Bierville de Carles Riba: opcions traductores i models de llengua literària». Anuari TRILCAT 3:39-6o.

_ Edèndum.

Massot i Muntaner, Josep. 2016. «Les Publicacions de l'Abadia de Montserrat i la censura». Dins VILAR DELL, Traducció i censura en el franquisme, 9-34.

Mengual, Josep. 2013. A dos tintas. Josep Janés, poeta y editor. Barcelona: Debate.

Moreno CANTANO, Antonio César. 2008. «La censura franquista y el libro catalán y vasco (1936-1975)». Dins Eduardo Ruiz Bautista, coord., Tiempo de censura. La represión cultural durante el franquismo, 143-171. Gijón: Ediciones Trea.

Moret, Xavier. 2012. Tiempo de editores. Historia de la edición en España, 1939-1975. Barcelona: Destino. 
MuÑoz Lloret, Teresa. 2006. Josep M. Castellet: retrat de personatge en grup. Barcelona: Edicions 62.

Núñez García, Laureano. 2008. «Fiore di poeti catalani: Pier Paolo Pasolini y Cataluña». Dins Assumpta Camps i Lew Zy вatow, ed., La traducción literaria en la época contemporánea: actas de la Conferencia Internacional «Traducción e Intercambio Cultural en la Época de la Globalización», 317-325. Frankfurt: Peter Lang.

— 2012. «De Dante a Pasolini. La traducción de la literatura italiana durante la dictadura franquista (1939-1975)». Transfer VII (1-2): 3-18.

ORDUÑA, Javier. 1988. El teatre alemany contemporani a l'Estat Espanyol. Barcelona: Publicacions de l'Institut del Teatre de Barcelona.

Ortega Sáez, Marta. 2011. «Narrativa y censura de Vita Sackville-West en la España de Franco (1939-1975)». Dins Coll-VINENT, EISNER \& GALlÉN, La traducció i el món editorial de postguerra, $65-80$.

OrTín, Marcel. 2002. «Els Dickens de Josep Carner i els seus crítics». Quaderns. Revista de Traducció 7: 121-151.

.2004. «Las traducciones, del Noucentisme a la actualidad». Dins Francisco

Lafarga i Luis Pegenaute, Historia de la traducción en España, 674-694. Salamanca: Ambos Mundos.

- 2011. «Aspectes institucionals i culturals de la reedició de traduccions. El cas de la Biblioteca Literària de l'Editorial Catalana». Dins Gabriella GAVAGNIN i Víctor MARTÍNEZ-GIL, ed., Entre literatures. Hegemonies i perifèries en els processos de mediació literària, 101-120. Lleida: Punctum / GELCC.

PARCerisas, Francesc. 1998. «Les traduccions de Marià Villangómez». Quaderns. Revista de Traducció 1: 35-52.

. 2007. «Manuel de Pedrolo, introductor a Catalunya de la narrativa nordamericana contemporània». Quaderns. Revista de Traducció 14: 39-48.

- 2009a. Traducció, edició, ideologia. Aspectes sociològics de les traduccions de la Bíblia i l’Odissea al català. Vic: Eumo.

. 2009b. «Montserrat Abelló, traductora amb motiu dels seus 90 anys». Quaderns. Revista de Traducció 16: 101-103.

- 2010. «La difusió de la literatura catalana en el món editorial espanyol del segle xx. Dins Gallén, Lafarga \& Pegenaute, Traducción y autotraducción entre las literaturas ibéricas, 193-220.

PARRA, Joan. 1998. «Pericay, Xavier; Toutain, Ferran. El malentès del noucentisme». Quaderns. Revista de Traducció 1: 160-162.

Pasqual, Marta. 2011a. "Joan Sales, editor de traduccions». Quaderns. Revista de Traducció 18: 41-50.

- 2011b. «Joan Sales: adaptador i editor de rondalles durant la postguerra». Dins Coll-Vinent, Eisner \& Gallén, La traducció i el món editorial de postguerra, 55-65. Pericay, Xavier, i Ferran Toutain. 1996. El malentès del Noucentisme. Barcelona: Proa. PIJOAn, Alba. 2003. «Entrevista a Jordi Arbonès». Quaderns. Revista de Traducció 9: 153-16o. 
PijoAn, Alba. 2005. «Aproximació a l'obra assagística de Jordi Arbonès sobre la traducció». Quaderns. Revista de Traducció 12: 33-40.

— 2007. «Anàlisi del mecanoscrit i la correcció de la traducció de Manuel de Pedrolo de Llum d'agost». Quaderns. Revista de Traducció 14: 57-66.

PLA, Xavier. 2009. «Ferran Canyameres, la creació de l'editorial Albor i la "fàbrica” Simenon». Quaderns. Revista de Traducció 16: 75-86.

— 2011. «Joan Sales, una traducció i una novella sense punt final».Quaderns. Revista de Traducció 18: 9-19.

Pons, Arnau, i Simona ŠCrABEC, ed. 2007. Camins de frontera, vol. 1. Barcelona: Institut Ramon Llull.

— ed. 2008. Camins de frontera, vol. 2. Barcelona: Institut Ramon Llull.

PROA. 2003. 75 anys a tot vent. Barcelona: Edicions Proa.

Puimedon, Pilar. 1996. «Joan Sales. La responsabilitat del supervivent». Tesi doctoral, Universitat de Barcelona.

Pujol, Carlos. 2011. «La traducció al castellà d'Incerta glòria». Quaderns. Revista de Traducció 18: 25-28.

Quer, Pere. 2011. «Aproximació a l'estudi de les traduccions en l'edició religiosa dels anys 6o. El cas de Nova Terra». Dins Coll-Vinent, EISNER \& Gallén, La traducció $i$ el món editorial de postguerra, 273-286.

Ramionet Lloveras, Enric. 2011. August Vidal. Entre Llagostera i Moscou. Una història personal dins la història del segle Xx. Llagostera: Ajuntament de Llagostera.

RAMIs, Josep Miquel. 2010. «Sebastià Juan Arbó, autotraductor». Dins GALLÉN, LAFARGA \& Pegenaute, Traducción y autotraducción entre las literaturas ibéricas, 335-347.

— 2011. «Autotraducció i Sebastià Juan Arbó: el cas de Terres de l’Ebre». Tesi doctoral, Universitat Pompeu Fabra.

. 2012. «Autotraducció i història d'un text literari. Hores en blanc. Notes d'un estudiant que va morir boig, de Sebastià Juan Arbó». Revista de Filología Románica 29, 2: 319-335.

- 2013a. «La autotraducción y el difícil encaje de sistemas literarios en contacto». EU-topías 5: 99-111.

- 2013b. «Autotraducció: ratificació i rectificació. El cas de Sebastià Juan Arbó». Dins Christian LAGARDE i Helena TANQUEIRo, ed., L'Autotraduction aux frontières de la langue et de la culture, 169-184. Llemotges: Lambert-Lucas.

- 2014. Autotraducció: de la teoria a la pràctica. Vic: Eumo.

Ripoll, Josep M. 2009. «El teixit contra la barbàrie: El corb i El cementiri marí per Xavier Benguerel». Quaderns. Revista de Traducció 16: 55-65.

RIPOLL, Ricard. 2007. «Ripoll i els Cants de Maldoror». Quaderns. Revista de Traducció 14: $67-75$.

Rodríguez EsPinOSA, Marcos. 2005. «Jordi Arbonès, traductor de la Fira de les vanitats (1984) de William Thackeray». Quaderns. Revista de Traducció 12: 59-75.

Rojas Claros, Francisco. 2013. Dirigismo cultural y disidencia editorial en España (1962-1973). Alicante: Publicaciones de la Universidad de Alicante. 
RUiz BAUTISTA, Eduardo. 2005. Los señores del libro: propagandistas, censores y bibliotecarios en el primer franquismo. Gijón: Trea. , coord. 2008. Tiempo de censura. La represión cultural durante el franquismo. Gijón: Ediciones Trea.

Ruiz Casanova, José Francisco. 2000. Aproximación a la historia de la traducción en España. Madrid: Cátedra.

_ 2011. «Presència catalana en Papeles de Son Armadans (1956-1979)». Dins ColLVinent, EISNER \& GALlÉn, La traducció i el món editorial de postguerra, 243-252.

_. 2012. «Agustí Bartra: Vida mexicana (americana) de un traductor».Anuari TRILCAT 2: 132-157.

RundLe, Christopher, i Kate STURGE. 2010. Translation under fascism. Houndmills: Palgrave Macmillan.

SALA-SANAHUJA, Joaquim. 2015a. «Bonaventura Vallespinosa. El teatre clàssic francès. Molière, Racine». Quaderns. Revista de Traducció 22: 111-121.

_ 2015b. «Miquel Martí i Pol, seqüències del traductor». Anuari TRILCAT 5: 35-57.

SALUdes I Amat, Anna Maria. 2001. «Italianística, Catalanística: relacions entre ambdues llengües i cultures (1900-2001)». Rassegna iberistica, 73: 21-37.

SALVAT, Ricard. 1985. «Sempre amb Carme Serrallonga». Quaderns de traducció $i$ interpretació 5/6:155-158.

SAN Vicente, Ricard. 2011. «Els traductors que venien de la URSS». Dins COLL-Vinent, EISNER \& GALLÉN, La traducció i el món editorial de postguerra, 11-22.

SAW ICKA, Anna. 2004. «Polacs i polonesos. Traducció literària català-polonès i polonèscatalà». Quaderns. Revista de Traducció 11:11-27.

Schjabal, Jan, i David Utrera. 2004. «Les traduccions en txec i eslovac d'obres literàries catalanes i viceversa». Quaderns. Revista de Traducció 11: 45-57.

ŠCrABEC, Simona. 2004. «Intercanvi literari entre Catalunya i Eslovènia». Quaderns. Revista de Traducció 11: 89-104.

SELLENT, Joan. 1998. «La traducció literària en català al segle xx: alguns títols representatius». Quaderns. Revista de Traducció 2: 23-32.

SimboR, Vicent. 2003. «La recepció del neorealisme italià». Dins Estudis de llengua i literatura catalanes XLVI. Miscellània Joan Veny, vol. 2, 79-297. Barcelona: Publicacions de l'Abadia de Montserrat.

— 2005. El realisme compromès en la narrativa catalana de postguerra. València: Institut Interuniversitari de Filologia Valenciana.

SopenA, Mireia. 2006. «Le franquisme contre la pensée. L'essai français sous la surveillance de la censure franquiste». Pandora. Revue d'Études Hispaniques 6: $253-266$.

- 2009. «Intellectuals i pensament sota la censura. Les traduccions de "Llibres a l'abast” (1936-1977)». Dins Kálmán Falu ba i Ildikó SzJıI, ed., Actes del Catorzè Colloqui Internacional de Llengua i Literatura Catalanes, 415-425. Barcelona: Publicacions de l'Abadia de Montserrat.

—. 2013. «Con vigilante espíritu crítico”. Els censors en les traduccions assagístiques d'Edicions 62». Quaderns. Revista de Traducció 20:147-161. 
Sopena, Mireia. 2015. «Los satélites de la cura diocesana. Censores eclesiásticos en la Barcelona de los sesenta». Dins Represura. Revista de Historia Contemporánea española en torno a la represión y la censura aplicadas al libro 1 (nova època): 66-92. _. 2016. «Diligent i irreductible. La censura eclesiàstica als anys seixanta». Dins VILARDELL, Traducció $i$ censura en el franquisme, 35-50.

Tree, Matthew. 2005. «Arbonès, Miller i Nin». Quaderns. Revista de Traducció 12: 77-81. TUR, Jaume. 1974. Maragall i Goethe. Les traduccions del Faust. Barcelona: Universitat de Barcelona.

Tusquets, Ester. 2005. Confesiones de una editora poco mentirosa. Barcelona: RqueR. UDINA, Dolors. 2005. «La correspondència de Jordi Arbonès». Quaderns. Revista de Traducció 12: 25-32.

—_. 2009. «Anna Murià: Genets cap a la mar, de J. M. Synge». Quaderns 16: 223-228. . 2010. «Gabriel Ferrater, traductor». Quaderns 17: 105-114.

VALL, Xavier. 1998. «Llorenç Villalonga i l'existencialisme». Els Marges 62: 105-116.

- 2000. «J. M. Castellet i l'“existencialisme”». Els Marges 66: 7-23.

- 2009. «L'existencialisme en la literatura catalana». Lluc 869, any LXXXVII: 28-33.

VALLVERdú, Francesc. 2013. «La traducció i la censura franquista. La meva experiència a Edicions 62». Quaderns. Revista de Traducció 20: 9-16.

VANDAELE, Jeroen. 2010. «It Was What it Wasn't: Translation and Francoism». Dins RUNDLE \& STURGE, Translation under fascism, 84-117.

Venuti, Lawrence. 2005. «Local Contingencies: Translation and National Identities». Dins Sandra BERMANN i Michael Wood, ed., Nation, Language and the Ethics of Translation, 177-202. Princeton: Princeton University Press.

VERGÉs, Josep C. 2007. Un país tan desgraciat: memòria compartida amb l'editor de Destino. Barcelona: Sd edicions.

VILARDELL, Laura. 2011. «Una aproximació a la collecció “Isard”». Dins ColL-VINENT, EISNER \& GALLÉN, La traducció $i$ el món editorial de postguerra, 253-272.

_. 2015. «Albert Camus y la censura franquista en la colección "Isard" de la Editorial Vergara». Represura 1 (nova època): 93-107.

- ed. 2016a. Traducció $i$ censura en el franquisme. Barcelona: Publicacions de l'Abadia de Montserrat. . 2016b. «La collecció “Isard”, d'Editorial Vergara, i la censura: el cas d'After many a summer». Dins VILARDELL, Traducció i censura en el franquisme, 171-180.

Ysàs, Pere. 2004. Disidencia y subversión: la lucha del régimen franquista por su supervivencia, 196o-1975. Barcelona: Crítica.

ZAвокLICKA, Bożena. 2011. «Les traduccions de literatura polonesa a Catalunya durant el règim franquista (1939-1975)». Dins Coll-Vinent, EISNer \& GAllén, La traducció i el món editorial de postguerra, 23-38.

Zaragoza, Gora, Juan José Martínez i José Javier Ávila-Cabrera, ed. 2015. «Traducción y censura. Nuevas perspectivas». Quaderns de Filologia, Estudis Literaris 20. 